Biologie Aujourd'hui, 209 (1), 3-33 (2015)

(C) Société de Biologie, 2015

DOI: $10.1051 /$ jbio/2015012

\title{
La machinerie moléculaire de sécrétion des neurotransmetteurs ${ }^{\star}$
}

\author{
Thomas C. Südhof \\ Departement of Molecular and Cellular Physiology, Stanford University School of Medicine, Howard Hughes Medical \\ Institute (SIM1)/Lorry Lokey Stem Cell Building, 265 Campus Drive, Room G1021, Stanford, CA 94305-5453, USA \\ Auteur correspondant : Thomas C. Südhof, tcs1@stanford.edu
}

\section{L'énigme de la sécrétion des neurotransmetteurs}

L'histoire scientifique des synapses est longue. La démonstration de leur fonction est due à Emil du Bois-Reymond (1816-1896), leur identification morphologique à des neuroanatomistes tels que Rudolf Kölliker (1817-1905) et Santiago Ramon y Cajal (1852-1934), et leur dénomination en 1897 à Michael Foster (1836-1907). Alors que la nature chimique de la transmission synaptique avait été suggérée par du Bois-Reymond, elle fut longtemps controversée, en raison de la rapidité stupéfiante avec laquelle elle se produit. Avec le temps toutefois, des preuves indiscutables établirent que la plupart des synapses font appel à des messagers chimiques, les neurotransmetteurs. Les contributions les plus importantes à ce sujet sont celles de Otto Loewi (1873-1961), Henry Dale (1875-1968), Ulf von Euler (1905-1983) et Julius Axelrod (1912-2004). En parallèle, le progrès décisif pour comprendre le mode de fonctionnement des synapses fut apporté par Bernard Katz (1911-2003), qui en élucida les principaux mécanismes (Katz, 1969). La plupart des analyses initiales sur les synapses ont fait appel à la jonction neuromusculaire, les synapses centrales n'ayant accédé au devant de la scène qu'au cours des décennies récentes. Les contributions les plus importantes de nombreux chercheurs, parmi lesquels George Palade, Rodolfo Llinas, Chuck Stevens, Bert Sackmann, Eric Kandel et Victor Whittaker, pour n'en citer que quelques-uns, non seulement confirmèrent les résultats principaux établis par Katz sur la jonction neuromusculaire mais révélèrent que

\footnotetext{
* La Fondation Nobel (www.Nobelprize.org) nous a autorisés à publier cette traduction de la conférence donnée par le Pr. Südhof lors de la remise du Prix Nobel 2013. Nous l'en remercions vivement ainsi que le Pr. Südhof. Les figures ont été reproduites dans la version originale de la conférence Nobel et les légendes y sont donc en anglais.
}

les synapses présentent une remarquable diversité de propriétés ainsi qu'une plasticité inattendue.

La propriété primordiale de la transmission synaptique est sa rapidité. Dans la plupart des cas, cette transmission dure seulement quelques millisecondes. Cette rapidité phénoménale est indispensable au travail du cerveau - sinon comment un gardien de but pourrait-il réagir à un tir en moins d'une seconde ou une ballerine pirouetter sans tomber? Les synapses diffèrent considérablement les unes des autres par des caractéristiques telles que leur force et leur plasticité mais elles opèrent toutes selon le même principe fondamental d'abord élucidé par Bernard Katz. Quand un potentiel d'action voyage le long d'un axone, il dépolarise les terminaisons nerveuses et ouvre les canaux calciques pré-synaptiques. L'influx calcique déclenche la libération du neurotransmetteur en moins d'une milliseconde, avec un délai sans doute inférieur à 100 microsecondes (Sabatini \& Regehr, 1996). De manière stupéfiante étant donné cette vitesse, la libération pré-synaptique s'accomplit par l'intermédiaire d'un trafic membranaire. Les terminaisons pré-synaptiques sont gorgées de vésicules synaptiques - de petits organites uniformes de $35 \mathrm{~nm}$ de diamètre - qui contiennent de fortes concentrations de neurotransmetteur. La libération est déclenchée lorsque le calcium induit la fusion éclair de ces vésicules à la membrane plasmique pré-synaptique dans une région spécialisée, dite zone active. La zone active est localisée très précisément en face de la densité post-synaptique qui contient les récepteurs des neurotransmetteurs; par conséquent les neurotransmetteurs sont libérés directement vers leurs récepteurs (figure 1).

La zone active est le principe organisateur qui assure la vitesse et la précision de la transmission synaptique. Cette zone recrute et ancre les vésicules synaptiques aux sites de libération, met les vésicules dans un état «amorcé » compétent pour la fusion, 


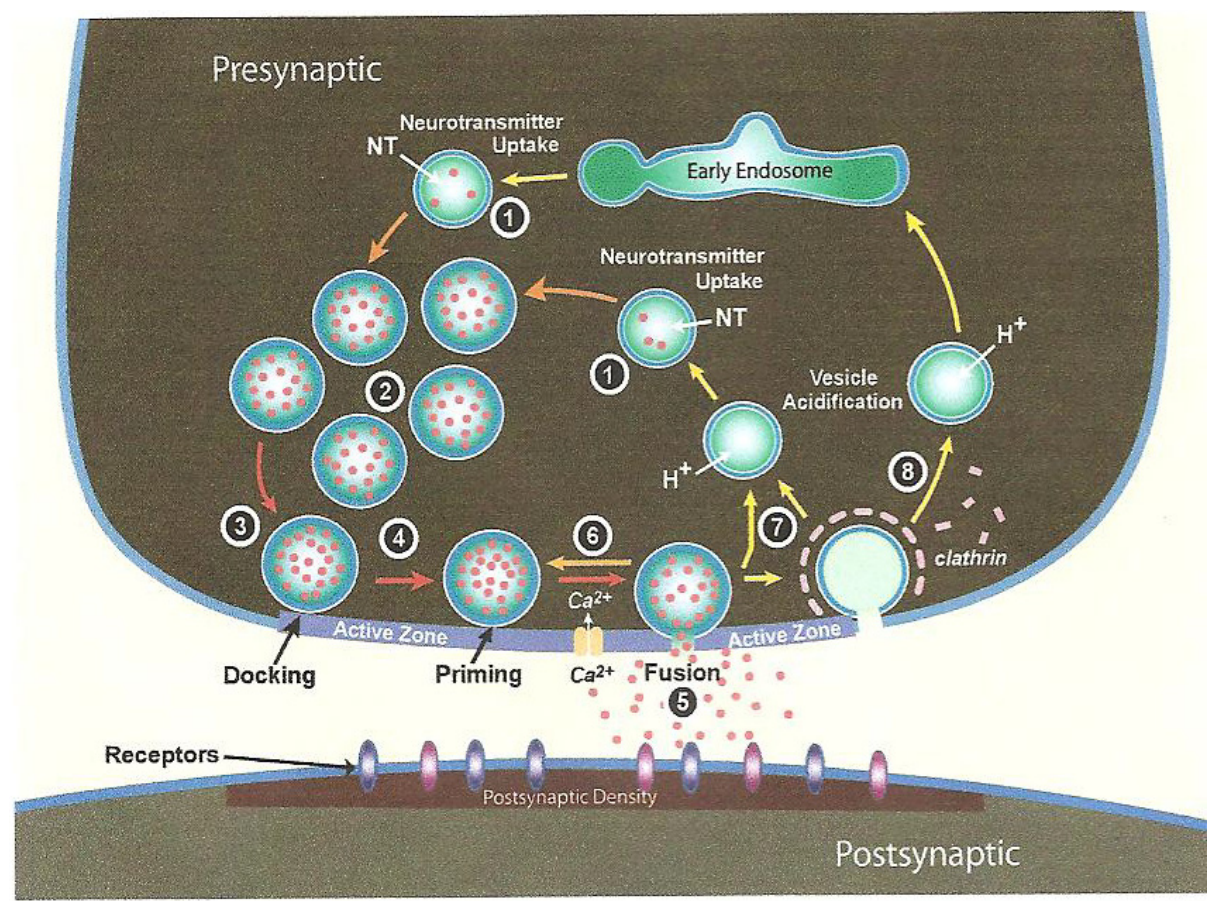

Fig. 1. Le cycle de la vésicule synaptique. Dans les terminaisons pré-synaptiques, un trafic membranaire cyclique actif est responsable de la libération du neurotransmetteur. Étape 1, les vésicules sont produites à partir des endosomes ou bien par recyclage après exo- et endocytose et se remplissent ainsi de neurotransmetteurs (NT); Étape 2, les vésicules sont transportées vers la zone active de la membrane plasmique pré-synaptique, d'où elles peuvent être recrutées pour l'exocytose ; Étape 3, les vésicules s'arriment à la zone active pré-synaptique au cours d'une réaction d'ancrage qui dépend des protéines Rab3/27 et de la protéine RIM (voir figure 14); Étape 4, les vésicules sont « activées », ce qui les rend compétentes pour la fusion déclenchée par le $\mathrm{Ca}^{2+}$; Étape 5 , le $\mathrm{Ca}^{2+}$ déclenche l'ouverture du pore de fusion, libérant les neurotransmetteurs; Étapes 6-8, les vésicules sont recyclées soit immédiatement après l'ouverture du pore de fusion (6, kiss-and-stay), soit par endocytose rapide probablement clathrine-dépendante (7, kiss-and-run), soit encore par une voie clathrine-dépendante qui implique un intermédiaire endosomal (8). Noter que la majeure partie des voies de recyclage a été clarifiée par les travaux classiques de Heuser \& Reese (1973), Cecarelli et al. (1973), et Zimmermann \& Whittaker (1977). Le dessin est adapté de Südhof \& Jahn (1991) et Südhof (2004).

prêt à répondre au déclenchement de la libération par le $\mathrm{Ca}^{2+}$, et arrime les canaux calciques à côté des sites d'ancrage (Südhof, 2012). En rapprochant les canaux calciques et les vésicules «amorcées » à la fente synaptique, la zone active permet dans le même temps un couplage étroit de la libération du neurotransmetteur à un potentiel d'action et de diriger cette libération vers la fente synaptique. Après l'exocytose, les vésicules synaptiques sont recyclées par différentes voies, en particulier par des mécanismes d'endocytose rapide, dits parfois «baiser au vol» (kiss-and-run) (Ceccarelli et al., 1973), ainsi que par des mécanismes d'endocytose plus lents impliquant des puits recouverts de clathrine (Heuser \& Reese, 1973; figure 1).

Comparée à la libération pré-synaptique du neurotransmetteur, sa réception post-synaptique est plus facile à expliquer, car elle est en grande partie réalisée par la liaison du transmetteur à des canaux ioniques contrôlés par les ligands. Les récepteurs postsynaptiques ionotropes sont des machines moléculaires complexes, qui sont groupées en face de la zone présynaptique active, et convertissent rapidement un signal neurotransmetteur en un signal ionique intracellulaire (figure 1). Toutefois la simplicité apparente des mécanismes post-synaptiques est trompeuse, car les récepteurs post-synaptiques des neurotransmetteurs sont sujets à des processus régulateurs complexes, incluant des trafics de vésicules, qui ne sont que partiellement compris. De plus, les voies de transduction post-synaptique du signal ont une organisation complexe et compartimentée qui diffère sensiblement d'une synapse à l'autre. Si l'on considère le modèle classique simple et pourtant complexe d'une synapse chimique, on ne peut que s'émerveiller devant l'ingéniosité de ce modèle, en ce qu'il apporte à la fois une grande rapidité et une surprenante plasticité de la transmission.

Lorsque j'ai démarré mon laboratoire en 1986, on connaissait par le détail les processus physiologique de libération des neurotransmetteurs. Pourtant 
on n'avait aucune compréhension mécanistique, ou d'hypothèse plausible, sur la fusion des vésicules synaptiques; comment le $\mathrm{Ca}^{2+}$ pouvait-il déclencher la fusion si rapidement? Comment la machinerie de libération était-elle organisée par la zone active présynaptique? Aucun des composants moléculaires de la synapse n'avait été caractérisé, aucun cadre conceptuel n'existait pour expliquer la plasticité extraordinaire ni la précision de la libération déclenchée par le $\mathrm{Ca}^{2+}$. Je me suis attaqué à cette question scientifique plutôt que d'étudier la réception postsynaptique, parce que j'étais fasciné par la rapidité de la libération déclenchée par le $\mathrm{Ca}^{2+}$. Celle-ci me paraissait incompréhensible, et j'étais intrigué par les éventuelles implications du mécanisme de libération pour d'autres réactions comportant un trafic membranaire, comme par exemple la sécrétion hormonale.

Dans le chapitre suivant, je donnerai un aperçu personnel de nos découvertes. Je présenterai notre travail dans le contexte des travaux d'autres collègues qui ont été nécessaires à la progression de nos recherches, mais, faute de place, je ne pourrai faire justice à beaucoup d'autres contributions tout aussi importantes. Nos travaux s'intègrent au sein d'une vaste communauté scientifique qui travaillait sur ces problèmes; j'essaierai de donner un récit équilibré du domaine dans l'espace qui m'est alloué.

\section{Anatomie moléculaire de la terminaison pré-synaptique}

Au départ, nous avons choisi une stratégie simple pour comprendre la libération des neurotransmetteurs : il s'agissait d'isoler et de cloner toutes les protéines majeures des terminaisons pré-synaptiques. En collaboration avec Richard Jahn, nous nous sommes focalisés sur les vésicules synaptiques, car on pouvait obtenir des préparations vésiculaires très pures en grandes quantités (Whittaker \& Sheridan, 1965; Südhof \& Jahn, 1991). Plus tard, nous avons étendu cette stratégie à la zone pré-synaptique active. Le but de ces expériences initiales était de construire un catalogue moléculaire des protéines pré-synaptiques, comme point de départ pour la dissection fonctionnelle de la libération.

Les premières protéines vésiculaires présynaptiques que nous avons purifiées et clonées ont été la synaptophysine (Südhof et al., 1987), le cytochrome b561 (Perin et al., 1988) les synapsines (Südhof et al., 1989a), les synaptobrévines (Südhof et al., 1989b; clonées indépendemment par R.H. Scheller et appelées «vesicle-associated membrane proteins » ou VAMP; Trimble et al., 1988), des composants de la pompe à protons (Südhof et al., 1989c; Perin et al., 1991a) et les synaptotagmines

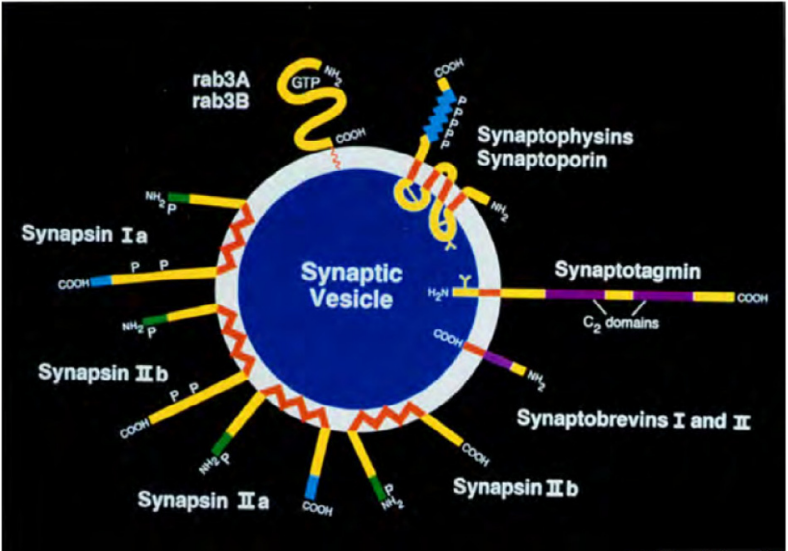

Fig. 2. Diagramme des protéines de la vésicule synaptique impliquées dans la libération des neurotransmetteurs, comme on l'interprétait en 1991. Lorsque l'effort pour cartographier l'anatomie moléculaire des vésicules synaptiques a commencé, cinq classes majeures de protéines étaient identifiées : les synapsines, considérées à l'époque comme les candidates majeures pour la régulation du relargage du neurotransmetteur (Südhof et al., 1984a), les protéines Rab3 (von Mollard et al., 1990), les synaptophysines (Südhof et al., 1987), les synaptotagmines (Perin et al., 1990) et les synaptobrévines/VAMP (Südhof et al., 1989b). Parmi toutes ces protéines, trois classes (Rab3, les synaptotagmines et les synaptobrévines) sont apparues comme cruciales pour la libération lors des études ultérieures. (Reproduit de Südhof \& Jahn, 1991).

(Perin et al., 1990; Geppert et al., 1991; Li et al., 1995a, 1995b). De plus, nous avons montré que la protéine Rab3, l'une des protéines liant le GTP dans le cerveau (initialement identifiée comme une séquence homologue de ras) (Touchot et al., 1987), est associée aux vésicules synaptiques, se liant et se séparant cycliquement des vésicules pendant l'exocytose (von Mollard et al., 1990, 1991).

Au début des années 1990, une caractérisation assez extensive de la vésicule synaptique en tant qu'organite avait émergé (Sudhöf \& Jahn, 1991; figure 2). Par la suite, une série d'autres protéines vésiculaires, incluant SVOP (Janz et al., 1998) et les SCAMP (Fernández-Chacón et al., 2000) ont été clonées par nous et par d'autres. En outre, nous avons étendu nos tentatives de caractériser la machinerie de libération à la zone active et avons identifié Munc18s (Hata et al., 1993), les complexines (McMahon et al., 1995), Munc 13s (Brose et al., 1995), CASK (Hata et al., 1996), les RIM (Wang et al., 1997), les RIM-BP (Wang et al., 2000) et les ELK (Wang et al., 2002; décrites indépendamment par Ohtsuka et al., 2002). Ces analyses ont été complétées par d'autres, identifiant comme protéines de la zone active les $\alpha$-liprines 
(Zhen \& Jin, 1999), bassoon (tom Diek et al., 1998) et piccolo (Wang et al., 1999; Fenster et al., 2000).

Après avoir élucidé les structures primaires d'un nombre croissant de protéines synaptiques, nous étions confrontés au défi de déterminer leurs fonctions. Nous avons décidé alors d'examiner ces molécules sans a priori, aussi systématiquement que possible, en associant des techniques allant de la biochimie à la biologie cellulaire, la génétique de la souris et l'électrophysiologie.

Comme je le raconterai ci-dessous, ces études ont permis une nouvelle compréhension de la libération des neurotransmetteurs. Cependant tous nos efforts n'ont pas été couronnés de succès et certaines protéines abondantes et conservées ne se sont pas révélées importantes. Par exemple, les synapsines et les synaptophysines ont des rôles ancillaires dans le cycle des vésicules synaptiques, qui peuvent être importants pour l'organisme entier tout en étant secondaires pour le processus basique de l'exo- et l'endocytose synaptiques (voir par exemple Rosahl et al., 1993 et 1995; Janz et al., 1999).

Dans la description qui suit, je distinguerai trois processus fondamentaux de la libération synaptique : la fusion membranaire, qui est le mécanisme de base de l'exocytose; le déclenchement par le $\mathrm{Ca}^{2+}$, événement clé qui commande la rapidité de la transmission synaptique; et enfin l'organisation spatiale de la machinerie de libération au niveau de la zone active, qui permet le couplage précis d'un potentiel d'action synaptique à une réponse post-synaptique.

\section{Mécanisme de fusion de la membrane synaptique}

\section{Les protéines SNARE et la fusion}

Les premières intuitions sur les mécanismes de fusion vésiculaire à la membrane plasmique présynaptique sont issues d'études sur les toxines tétanique et botulinique. Ces agents pathogènes, qui causent le tétanos et le botulisme, sont parmi les plus puissantes des neurotoxines connues et ont également une utilité thérapeutique (Grumelli et al., 2005). Ce sont des métalloprotéases qui, à des concentrations nanomolaires, bloquent la libération du neurotransmetteur en empêchant la fusion des vésicules synaptiques à la membrane plasmique présynaptique.

En 1992, des travaux - auxquels nous avons collaboré - dans les laboratoires de Cesare Montecucco, Heiner Niemann et Reinhard Jahn ont montré que ces deux toxines bloquent la fusion des vésicules par la scission protéolytique du complexe synaptobrévine-2/ VAMP (Link et al., 1992; Schiavo et al., 1992).
L'année suivante, les mêmes laboratoires montrèrent que d'autres types de toxines botuliques scindent deux autres protéines membranaires synaptiques, SNAP-25 et syntaxine-1 (Blasi et al., 1993a, 1993b; Schiavo et al., 1993). De plus, nous avons démontré qu'une isoforme ubiquitaire de la synaptobrévine (la cellubrévine) est aussi un substrat de la toxine tétanique, suggérant une fonction générale de molécules analogues à la synaptobrévine dans la fusion membranaire (McMahon et al., 1993). Ensemble, ces résultats apportaient la première preuve, la plus indiscutable à ce jour, que la synaptobrévine, SNAP25 et la syntaxine sont des composants essentiels de la machinerie de fusion membranaire pré-synaptique. Comme nous allons le voir, des données sur la façon dont ces protéines, plus tard appelées protéines SNARE (pour Soluble NSF-Attachement protein REceptors), fonctionnent, vinrent d'études menées en parallèle dans le laboratoire de James Rothman.

Rothman étudiait la fusion membranaire par reconstitution chimique du trafic vésiculaire entre les compartiments du Golgi (Balch et al., 1984). À l'aide de ce test, Rothman isola un facteur (appelé NSF) sensible à la N-éthyl-maléimide et des protéines adaptatrices au NSF, qui ancrent le NSF aux membranes (désignées SNAP, une malheureuse coïncidence d'acronymes avec SNAP-25). Le NSF et les SNAP sont essentiels pour la fusion in vitro dans le test de Rothman; ces protéines sont des homologues des gènes de levure impliqués dans la sécrétion, suggérant une fonction de base dans le trafic membranaire (Wilson et al., 1989; Clary et al., 1990). Dans une étude clé, le laboratoire de Rothman utilisa alors du NSF et des SNAP comme matrice d'affinité pour purifier des « récepteurs » de SNAP (i.e., SNARE) à partir du cerveau, la source la plus riche en ces récepteurs. Ils isolèrent alors la synaptobrévine-2, la syntaxine-1, et SNAP-25, au moment même où ces protéines se révélaient être les substrats des toxines botulique et tétanique (Söllner et al., 1993a). Par la suite, Rothman, en collaboration avec Richard Scheller, montra que la synaptobrévine-2, la syntaxine-1 et SNAP-25 forment un complexe et que ce complexe est dissocié par le NSF qui agit comme une ATPase (Söllner et al., 1993b). Cette expérience tout à fait remarquable permettait d'expliquer pour la première fois comment ces protéines pouvaient fonctionner au cours de la fusion, bien qu'il ait fallu encore plusieurs années pour démontrer de manière indiscutable ce mécanisme. En collaboration avec Heiner Niemann, nous avons trouvé que les complexes SNARE résistent au SDS et sont extrêmement solides, et que seul le complexe SNARE - mais non les protéines SNARE individuelles - se lie aux SNAP et au NSF, tandis que seules les protéines SNARE libres, et non les protéines SNARE en complexe, sont des substrats 
pour les toxines botulique et tétanique (Hayashi et al., 1994; McMahon et al., 1995).

L'ensemble de ces données suggérait que la formation des complexes SNARE entre les vésicules synaptiques et la membrane plasmique permettait la fusion; cependant le mécanisme de la fusion restait obscur. Une des hypothèses tenait que NSF et les SNAP étaient les protéines de fusion elles-mêmes, les protéines SNARE assurant la spécificité de la réaction de fusion en tant que récepteurs, après que les complexes SNARE se sont assemblés (Söllner et al., 1993a, 1993b). Motivés par les données des toxines botulique et tétanique, nous étions en faveur de l'hypothèse alternative selon laquelle les protéines SNARE, en particulier la synaptobrévine, étaient directement impliquées dans la fusion, bien que nous en ignorions le mécanisme (Südhof et al., 1993).

Deux expériences clés devaient ultérieurement clarifier l'implication de NSF/SNAP ou des SNARE dans la fusion membranaire. D'abord le laboratoire de Bill Wickner montra élégamment que, dans les essais sur la fusion des vacuoles de levure, le NSF de la levure n'était pas impliqué dans la fusion, mais qu'il était simplement requis pour activer les protéines SNARE avant la fusion et recycler la machinerie SNARE après la fusion (Mayer et al., 1996). Ensuite, dans une expérience qui fit date, Reinhard Jahn et John Heuser démontrèrent que les complexes SNARE s'assemblent en parallèle, de telle sorte que leur assemblage contraint les régions transmembranaires C-terminales des protéines SNARE à un contact étroit (Hanson et al., 1997).

Cette observation déterminante de Heuser et Jahn fournit un modèle mécanistique du rôle des protéines SNARE dans la fusion, à savoir celui d'une fermeture éclair fonctionnant de $\mathrm{N}$ - vers $\mathrm{C}$ - et forçant au contact les régions transmembranaires $\mathrm{C}$-terminales. Ce modèle a été confirmé rapidement par des études biophysiques et par cristallographie (Lin \& Scheller, 1998; Poirier et al., 1998; Sutton et al., 1998) puis affiné par Rothman et d'autres grâce à des reconstitutions in vitro avec des liposomes (Weber et al., 1998). C'est maintenant le modèle standard dans ce domaine.

\section{Les protéines SM sont les partenaires obligatoires de SNARE pour la fusion membranaire}

En 1993, alors que les protéines SNARE étaient en voie d'identification comme protéines de fusion membranaire, nous avons recherché d'autres composants de la machinerie de fusion par chromatographie d'affinité sur de la syntaxine-1 immobilisée (Hata et al., 1993). Nous avons isolé une protéine de $65 \mathrm{KDa}$, que nous avons appelée Munc18-1 de par son homologie de séquence avec le gène unc18 de C. elegans (figure 3a). Sidney Brenner avait isolé les vers mutants unc18 parce que ils ne remuaient pas normalement (ils étaient incoordinés) mais la fonction du gène unc18 était inconnue (Brenner, 1974). Cependant, parce que Munc18 se liait à la machinerie de fusion membranaire et parce que le unc18 de C. elegans était essentiel pour le mouvement, nous avons émis l'hypothèse selon laquelle Munc18-1 serait un composant intrinsèque de la machinerie de fusion et coopérerait avec les protéines SNARE pour la fusion (figure 3a).

D'autres analyses ont révélé que Munc18-1 était également l'homologue de sec1, le premier gène isolé par Peter Novick et Randy Schekman dans des cribles de mutants de sécrétion chez la levure. La fonction de sec1 était inconnue, comme celle de unc18, (Novick \& Schekman, 1979), mais cette homologie a conduit certains chercheurs à désigner Munc-18 sous l'appellation de n-sec1 ou rb-sec1 (Garcia et al., 1994, Pevsner et al., 1994). Plusieurs autres homologues de Sec1p et Munc18 ont été décrits par la suite et la famille génique est maintenant connue comme celle des «protéines Sec1/Munc18-like » (protéines SM; Rizo \& Südhof, 2012).

Après la découverte de Munc 18-1, une grande confusion, nourrie par des observations paradoxales, s'est établie à propos de sa fonction. D'un côté, chez la levure, les mutations de sec1 bloquaient la fusion (Novick \& Schekman, 1979), chez la drosophile la délétion du gène Munc18-1 abolissait la transmission synaptique (Harrison et al., 1994) et chez la souris la délétion de Munc 18-1 annihilait la libération des neurotransmetteurs (Verhage et al., 2000; figure 3b). Ces résultats suggéraient un rôle essentiel de Munc 18-1 dans la fusion, une hypothèse renforcée par les analyses élégantes de Novick, démontrant que Sec1p de la levure se lie aux complexes SNARE (Carr et al., 1999) et agit en aval de leur assemblage (Grote et al., 2000). D'un autre côté, nous avions montré que la syntaxine prend une conformation «fermée » quand elle est en dehors du complexe SNARE. Son domaine N-terminal Habc est alors replié sur le motif SNARE, et Munc18-1 se lie spécifiquement à cette conformation fermée (Dulubova et al., 1999). Les domaines Habc des syntaxines sont conservés et couvrent la moitié de leurs séquences, tandis que les motifs SNARE de ces molécules forment des complexes SNARE en s'assemblant avec les motifs SNARE semblables des synaptobrévines et de SNAP25 ou de leurs homologues pour former un faisceau à quatre hélices (figure 3c; Fernandez et al., 1998; Sutton et al., 1998). En conséquence, dans la conformation fermée de la syntaxine, l'interaction intramoléculaire du domaine Habc avec le motif SNARE empêche la syntaxine-1 de former le complexe SNARE. Ceci suggère que Munc18-1 soit un régulateur négatif de l'assemblage du complexe SNARE. Paradoxalement, Munc18-1 semble donc à la fois être nécessaire à la 


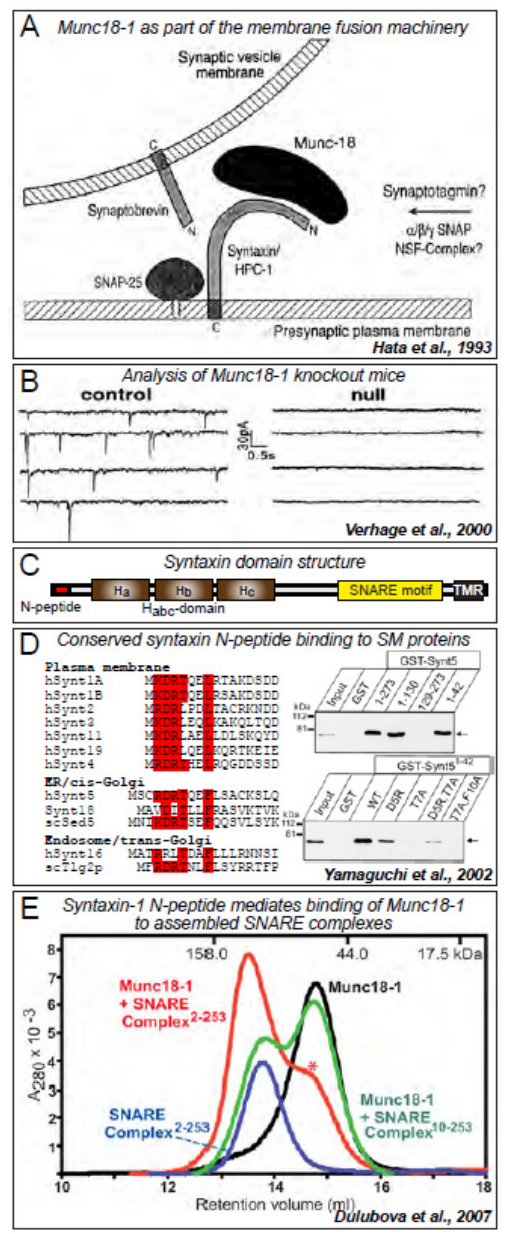

Fig. 3. Définition des interactions des protéines Sec1/Munc18-like (protéines « SM ») avec les syntaxines et le complexe SNARE pendant la fusion des vésicules synaptiques. (A) Diagramme des interactions de Munc18-1/SNARE proposées dans la description de Munc18-1 (Munc18, dans la figure) comme une protéine liant la syntaxine-1 et contribuant à la machinerie de fusion (reproduit de Hata et al., 1993). (B) Démonstration que Munc18-1 est essentiel pour la fusion des vésicules et ne fonctionne pas comme un régulateur négatif de la fusion. L'activité synaptique a été enregistrée dans le cortex de souris de type sauvage («control») et Munc18-1 KO («null »). Ces tracés montrent le silence électrique total en l'absence de Munc18-1 (reproduit de Verhage et al., 2000). (C) Structure des syntaxines : composées d'une séquence N-terminale conservée (N-Peptide), d'un domaine Habc à trois hélices $\alpha$, replié de manière autonome (Fernandez et al., 1998), du motif SNARE qui forme le complexe SNARE en se liant avec les séquences homologues des synaptobrévines et de SNAP25 et une région transmembranaire C-terminale (TMR). En dehors du complexe SNARE, les syntaxines adoptent une conformation « fermée » dans laquelle le domaine Habc N-terminal se replie sur le motif SNARE, verrouillant ce domaine et empêchant l'assemblage du complexe (Dulubova et al., 1999). (D) Découverte d'un motif conservé de la séquence N-terminale des syntaxines qui est responsable de la liaison de la plupart des protéines SM à leurs syntaxines apparentées. Un alignement de séquences N-terminales de syntaxines est montré à gauche (en rouge, les résidus conservés impliqués dans la liaison des protéines SM) et les immunoblots des expériences de liaison originelles à droite; ils démontrent que le N-terminal de la syntaxine-5 ER/Golgi se lie à la protéine SM Sly1 d'une manière dépendante du motif conservé de la séquence N-terminale de la syntaxine 5 (reproduit de Yamaguchi et al., 2002). (E) Démonstration par filtration sur gel d'un complexe stable contenant Munc18-1 lié à des complexes SNARE. Le profil d'élution de Munc18-1 et d'un complexe SNARE (contenant la séquence N-terminale entière de la syntaxine 1) a été analysé soit individuellement (tracés noir et bleu) soit avec un complexe SNARE contenant la séquence N-terminale complète de la syntaxine 1 (tracé rouge), soit avec la syntaxine- 1 tronquée de 8 résidus en N-terminal (tracé vert). Notez qu'en présence de complexes SNARE comprenant la syntaxine-1 entière, la plus grande partie de Munc18-1 est éluée avec le complexe SNARE, alors qu'en présence de complexes SNARE comportant une syntaxine-1 N-terminale tronquée, Munc18-1 n'est plus éluée avec le complexe SNARE (reproduit de Dubulova et al., 2007). 
fusion vésiculaire, et dans le même temps empêcher la fusion en bloquant l'assemblage du complexe SNARE.

Nous avons trouvé la solution à cette apparente contradiction lorsque nous avons observé, en collaboration avec Josep Rizo, que chez les vertébrés comme chez la levure, la protéine SM impliquée dans le transport vésiculaire du réticulum endoplasmique vers l'appareil de Golgi (Sly1) se lie à des syntaxines apparentées (syntaxine- 5 et -18 chez les vertébrés; Sed5p et Ufe1p chez la levure) via un court peptide N-terminal conservé (le « N-peptide »; Yamaguchi et al., 2002; figures $3 \mathrm{C}$ et $3 \mathrm{D})$. Nous avons par ailleurs trouvé que le même mécanisme s'applique à une autre protéine SM - Vps45 - qui est impliquée dans la fusion endosome/transGolgi et qui se lie à sa syntaxine-16 apparentée (Tlgp2p chez la levure), également par l'intermédiaire d'une séquence N-peptidique très voisine (Dulubova et al., 2002). Grâce à ce mécanisme de liaison, ces protéines SLM pourraient rester associées à leurs syntaxines pendant toute la durée de l'assemblage du complexe SNARE (en accord avec les études de Novick sur Sec1p (Grote et al., 2000; notez toutefois que les détails de la liaison de Sec1p au complexe SNARE chez la levure peuvent être différents). Nous avons observé que les syntaxines de la membrane plasmique des vertébrés contiennent une séquence N-terminale conservée extrêmement similaire, nous poussant à rechercher un mode de liaison similaire de Munc18-1 à la syntaxine-1.
En effet, nous avons trouvé que Munc18-1 se lie étroitement aux complexes SNARE assemblés, sous la dépendance du N-peptide de la syntaxine-1 (figure 3E; Dulubova et al., 2007). Le complexe Munc18-1/SNARE assemblé restait stable pendant la chromatographie d'exclusion stérique, mais était dissocié par la délétion du N-peptide de la syntaxine (figure 3E). Le laboratoire de James Rothman fit simultanément des observations similaires (Shen et al., 2007). La fusion du seul épitope Myc au peptide-N de la syntaxine 1 suffisait à inhiber ce mode de liaison, alors que la liaison de Munc18-1 à la forme monomérique fermée de la syntaxine-1 ne nécessitait pas le peptide $\mathrm{N}$ de la syntaxine.

Considérés dans leur ensemble, ces résultats montraient que Munc18-1 se lie à la syntaxine-1 de deux manières séquentielles qui impliquent des conformations différentes de la syntaxine-1 (figure 4) : un mode spécifique de l'exocytose au cours duquel Munc18-1 se lie à la syntaxine-1 «fermée » indépendamment du peptide-N (Dulubova et al., 1999) et un mode général partagé avec d'autres interactions protéines $\mathrm{SM} /$ complexe SNARE via le peptide-N de la syntaxine, et interagit en outre avec d'autres éléments du complexe SNARE (Dulubova et al., 2007).

Quelles sont les fonctions des deux modes de liaison de Munc18-1 aux protéines SNARE, et lequel est le plus important pour la fusion? Des expériences de compétition du peptide initial dans la synapse du

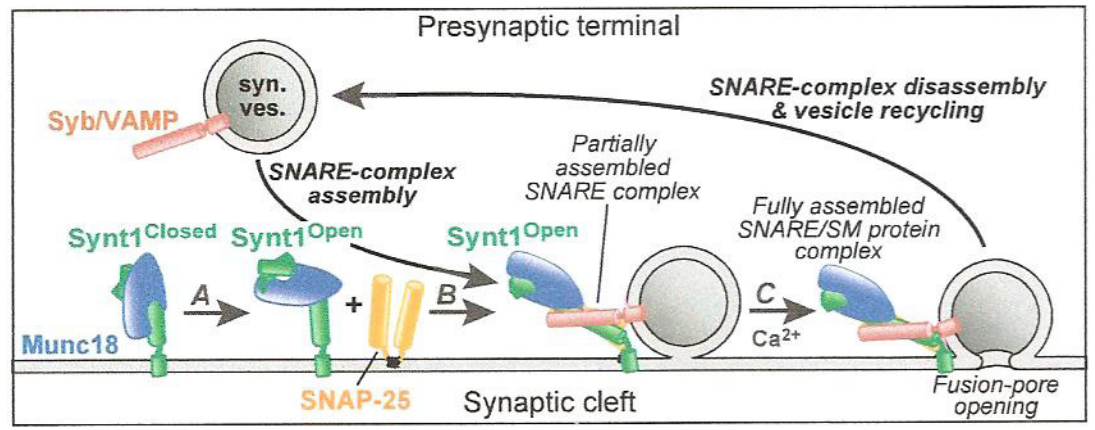

Fig. 4. Changements conformationnels des protéines SNARE et SM responsables de la fusion des vésicules synaptiques. Avant la fusion, la syntaxine-1 présente par défaut une conformation « fermée » qui lie Munc18-1 par une interaction ne nécessitant pas le domaine N-ter de la syntaxine-1 (Dulubova et al., 1999). Dans la réaction $A$, la syntaxine-1 est ouverte (probablement par une catalyse opérée par Munc 18-1; Ma et al., 2011) pour initier l'activation de la vésicule synaptique. Dans la réaction $B$, les complexes SNARE s'assemblent partiellement par « fermeture éclair » de N- vers C-terminal (Hanson et al., 1997), tandis que Munc18-1 reste associée avec la syntaxine-1 pendant l'assemblage des complexes SNARE par l'intermédiaire de sa liaison au N-peptide de la syntaxine (Khvotchev et al., 2007). Dans la réaction $C$, le $\mathrm{Ca}^{2+}$ déclenche l'ouverture du pore de fusion en stimulant la finalisation de l'assemblage du complexe SNARE; Munc18-1 contribue à ce processus et est indispensable à l'ouverture du pore pendant cette étape, car son association permanente avec les complexes SNARE est essentielle à cette ouverture (Zhou et al., 2013a). Après la fusion, les vésicules sont endocytées (voir figure 1) et les complexes SNARE sont désassemblés par l'ATPase NSF et sa protéine adaptatrice SNAP (qui n'a pas de relation à la protéine SNARE SNAP-25). Munc18-1 reste associée à la syntaxine-1 et retourne à son interaction hétérodimérique avec la syntaxine-1 en conformation « fermée ». Il y a donc deux transitions de conformation majeures pendant l'exocytose : l'ouverture de la syntaxine-1 avec réarrangement du mode de liaison de Munc18-1, et l'assemblage des protéines SNARE dans un complexe SNARE. 
« calice de Held» ont montré que le déplacement du N-terminal de la syntaxine-1 de Munc18-1 inhibe la fusion des vésicules synaptiques (Khvotchev et al., 2007). Des études ultérieures ont décrit comment des mutations de Munc18-1, qui diminuent la liaison de cette molécule aux séquences $\mathrm{N}$-terminales de la syntaxine-1, diminuent également la fusion (Deak et al., 2009). Il faut noter que dans une étude plus tardive, où ce résultat était récusé à l'aide de mutations similaires mais plus modestes (Meijer et al., 2012), les mutations Munc18-1 ne provoquaient qu'une diminution partielle de la liaison au peptide- $\mathrm{N}$ de la syntaxine 1. Dans ces travaux, toutes les expériences étaient conduites en forte surexpression, ce qui pouvait évidemment compenser la diminution de l'affinité de liaison. De plus chez C. elegans, des expériences ont révélé que le peptide- $\mathrm{N}$ était essentiel pour la fusion, mais n'avait pas besoin d'être sur la syntaxine-1 pour fonctionner, du moment qu'il était positionné près des complexes SNARE (Rathore et al., 2010). Finalement, nous avons montré que dans les synapses de mammifère, le peptide- $\mathrm{N}$ de la syntaxine-1 était également nécessaire à la fusion dans les conditions physiologiques (Zhou et al., 2013b).

Ces expériences démontrent que la liaison de Munc18-1 à la syntaxine « ouverte » à l'intérieur du complexe SNARE est essentielle pour la fusion et valident la fonction de Munc18-1 - analogue à celle de Sec1p - comme composant intrinsèque de la machinerie de fusion. Quel est donc alors le rôle de la liaison de Munc18-1 à la syntaxine «fermée »? Pour tester ce rôle, nous avons créé des souris knock-in chez lesquelles la syntaxine se trouvait constitutivement « ouverte $»$ (syntaxine-1 open), et donc la liaison de Munc18-1 à la syntaxine «fermée » y était inhibée (Gerber et al., 2008). Chez ces souris, Munc18-1 et la syntaxine-1 étaient toutes deux déstabilisées et leur niveau diminué, confirmant la notion que que le complexe Munc18-1 /syntaxine -1 fermée stabilise les deux protéines (Verhage et al., 2000). Par ailleurs, dans les synapses à syntaxine-1 ouverte, l'activation des vésicules était plus faible, probablement parce que moins de créneaux étaient disponibles pour la fusion des vésicules (Gerber et al., 2008; Acuna et al., 2014).

Cependant ces synapses à syntaxine-1 ouverte ont une probabilité de libération $\mathrm{Ca}^{2+}$-dépendante fortement augmentée et la fusion y est accélérée. Même la fusion des vésicules individuelles, évaluée d'après la cinétique d'évènements de libération uniques (mini), est plus rapide dans les synapses à syntaxine-1 ouverte que dans les synapses de type sauvage (Acuna et al., 2014). Ces données, ainsi que l'observation selon laquelle le domaine Habc de la syntaxine-1 n'est pas essentiel pour la fusion (Zhou et al., 2013a), démontrent que la liaison de Munc18-1 à la conformation fermée de la syntaxine-1 n'est pas requise pour la fusion, alors que la liaison à la conformation « ouverte » dans le complexe SNARE est nécessaire. La liaison de Munc18-1 à la conformation fermée de la syntaxine-1 servirait à deux autres fonctions : stabiliser les deux protéines dans le complexe, et diriger l'assemblage du complexe SNARE; elle régulerait ainsi le taux de fusion.

\section{Comment les SNARE et les protéines SM médient-elles la fusion?}

En principe, les protéines SNARE interviennent dans la fusion par un mécanisme simple : elles sont attachées aux deux membranes destinées à fusionner et forment un complexe «trans » qui implique le «zippage » progressif du complexe de faisceaux à quatre hélices dans une direction $\mathrm{N}$ - à C-terminale, en contraignant les membranes prêtes à fusionner à une proximité étroite et en déstabilisant leurs surfaces. Ce processus ouvre un pore de fusion, dont l'expansion convertit ensuite les complexes SNARE «trans » en complexes « cis » qui sont ensuite dissociés par les protéines adaptatrices NSF et SNAP, permettant ainsi un recyclage des vésicules et des protéines SNARE pour un autre cycle de fusion.

$\mathrm{Au}$ moins deux questions importantes se posent alors. D'abord, les protéines SNARE agissent-elles surtout comme des générateurs d'énergie pour attirer les membranes les unes vers les autres (ce qui pourrait être suffisant pour induire leur fusion in vitro), ou bien les protéines SNARE ouvrent-elles en fait le pore de fusion? Deuxièmement, quelle est précisément la fonction des protéines SM dans la fusion - pourquoi sont-elles requises?

In vitro, les régions transmembranaires de la synaptobrévine et de la syntaxine-1 interagissent dans le plan de la membrane. Les motifs SNARE de ces protéines forment une hélice $\alpha$ rigide et continue avec leurs régions transmembranaires, suggérant une contribution active de ces régions à la formation du pore de fusion (Stein et al., 2009). Cependant, au cours d'expériences récentes, nous avons trouvé que la synaptobrévine et la syntaxine-1 médient encore la fusion lorsqu'elles sont toutes deux attachées à leur membrane d'origine par des ancres lipidiques, et non pas par des régions transmembranaires, ce qui démontre que les régions transmembranaires ne sont pas des composantes essentielles de la machinerie de fusion (Zhou et al., 2013b). Ces résultats étayent l'idée que les protéines SNARE agissent comme des générateurs d'énergie, et que leurs régions transmembranaires n'agissent pas comme des catalyseurs de la fusion.

Que font donc les protéines SM dans la fusion? Le fait qu'elles soient requises de manière continue pendant l'assemblage du complexe SNARE est un argument en faveur d'un rôle d'organisateur permettant 
l'assemblage correct de ce complexe; alternativement, elles pourraient empêcher l'émergence de complexes inappropriés, ou bien encore être des catalyseurs d'assemblages lipidiques pendant la fusion. Actuellement, aucune donnée concluante ne permet de trancher dans un sens ou dans l'autre, et il est certain que cette question occupera nombre d'entre nous pour les années à venir.

\section{Les chaperonnes SNARE sont essentielles pour maintenir l'intégrité de la terminaison pré-synaptique}

Les neurones émettent des potentiels d'action par bouffées ou par trains, avec de fortes fréquences, souvent au-delà de $100 \mathrm{~Hz}$. Chaque événement de libération de neurotransmetteur implique le repliement et le dépliement de protéines SNARE réactives, exposant le cytosol pré-synaptique au repliement défectueux éventuellement délétère des protéines SNARE et à la formation de complexes inappropriés par des motifs SNARE réactifs. Il n'est donc pas surprenant que les neurones expriment des chaperonnes spécialisées qui guident le repliement correct des protéines SNARE, et que la délétion de ces chaperonnes conduise à la neurodégénération.

Nous avons identifié deux classes de ces molécules, $\operatorname{CSP} \alpha$ (pour Cysteine-String Protein $\alpha$, nommée ainsi parce qu'elle contient une chaîne éponyme de résidus cystéine palmytoïlés pour amarrer la $\operatorname{CSP} \alpha$ à la membrane de la vésicule synaptique; Gundersen et al., 1994) et les synucléines (nommées ainsi parce que on a d'abord pensé que ces protéines pouvaient aussi résider dans le noyau; Maroteaux et al., 1988).

Notre découverte de la fonction « chaperonne » de ces molécules SNARE était pure sérendipité. Nous avons trouvé que la délétion de $\operatorname{CSP} \alpha$ provoque une neurodégénérescence massive qui tue les animaux affectés en 3 à 4 mois; elle est due à une altération de la formation du complexe SNARE (Fernández-Chacón et al., 2004).

Il est étonnant que cette neurodégénérescence soit réprimée par une surexpression modeste de l' $\alpha$-synucléine (Chandra et al., 2005). À la suite de ces observations, nous avons montré que $\operatorname{CSP} \alpha-$ qui contient un domaine DNA-J et forme, avec Hsc70 et la protéine $\mathrm{SGT}$ à domaine tétratricopeptide répété, un complexe chaperon catalytique dépendant de l'ATP (Tobaben et al., 2000) - catalyse le repliement correct de SNAP25, rendant SNAP25 compétente pour l'assemblage du complexe SNARE (Sharma et al., 2011a, 2011b, 2012). Chez les souris KO pour $\operatorname{CSP} \alpha$, le repliement défectueux de SNAP25 altère l'assemblage du complexe SNARE qui, à son tour, provoque une neurodégénérescence. L' $\alpha$-synucléine pare à cette neurodégénérescence en promouvant l'assemblage du complexe par une activité chaperonne non classique, ATP-indépendante (Burré et al., 2010).

Quoique ces observations aient mis au jour une facette intéressante de la biologie de la protéine SNARE, nous ne comprenons pas encore en quoi les activités physiologiques de l' $\alpha$-synucléine sont liées à son rôle neurotoxique dans la maladie de Parkinson. Une hypothèse séduisante serait que l'agrégation de l' $\alpha$ synucléine dans cette maladie prive les neurones de toute l' $\alpha$-synucléine fonctionnelle disponible, et cause ainsi le repliement défectueux, lui-même délétère. Des hypothèses alternatives, par exemple une activité non physiologique toxique, directe, des oligomères de l' $\alpha$-synucléine, sont également plausibles.

\section{Le déclenchement de la fusion par le $\mathrm{Ca}^{2+}$ : les synaptotagmines et d'autres}

Alors que notre travail sur la fusion des membranes progressait, nous étudiions également une question voisine : comment la libération du neurotransmetteur par fusion des membranes vésiculaires est-elle déclenchée par le $\mathrm{Ca}^{2+}$ ? Dès mon entrée dans le laboratoire de Victor Whittaker à Göttingen, j'ai été fasciné par cette question. L'importance critique de la libération déclenchée par le calcium dans le fonctionnement cérébral m'intriguait, sa rapidité invraisemblable et sa plasticité me rendaient perplexe et la ressemblance de l'exocytose des vésicules synaptiques induite par $\mathrm{Ca}^{2+}$ à d'autres types d'exocytose impliquant également un déclenchement calcique, par exemple ceux qui sous-tendent la sécrétion hormonale, la dégranulation des mastocytes, ou la fécondation, me suggérait que comprendre ce phénomène pouvait éclairer d'une manière générale les processus de signalisation cellulaire. Bien que certaines découvertes clés sur les synaptotagmines aient été faites en même temps que celles qui concernaient les protéines SNARE et SM, le travail sur les synaptotagmines a nécessité un laps de temps plus long pour satisfaire toutes les critiques, même les plus sévères, et quelquesunes des plus importantes observations sont toutes récentes.

\section{Découverte de la synaptotagmine-1 : identification de domaines $\mathrm{C} 2$ aussi versatiles que les domaines de liaison au $\mathrm{Ca}^{2+}$}

$\mathrm{Au}$ cours de nos travaux sur l'anatomie moléculaire des synapses, nous avons cherché un senseur calcique candidat qui puisse intervenir dans le déclenchement de l'exocytose vésiculaire. Lorsque nous avons purifié et cloné la synaptotagmine (Syt1) - qui avait déjà été identifiée comme une protéine de vésicule synaptique 
à l'aide d'un anticorps monoclonal préparé contre des synaptosomes (Matthew et al., 1981) -, nous avons été intrigués par sa structure primaire parce que Syt1 avait deux domaines $\mathrm{C} 2$ ancrés à la membrane de la vésicule par une région transmembranaire (Perin et al., 1990; figures 2 et 5a). À cette époque, on ne savait rien sur les domaines $\mathrm{C} 2$, si ce n'est qu'ils représentaient la « $2^{\text {ème }}$ séquence constante $»$ dans les isozymes classiques de la protéine-kinase C (Coussens et al., 1986). Puisque ces isozymes sont régulés par le $\mathrm{Ca}^{2+}$ et interagissent avec les phospholipides, nous avons supposé que les domaines $\mathrm{C} 2$ de la synaptotagmine pouvaient être des modules de liaison au $\mathrm{Ca}^{2+}$ interagissant avec les phospholipides, et que Syt1 pouvait être un senseur calcique pour la libération vésiculaire (Perin et al., 1990). Explorant cette hypothèse pendant deux décennies, nous avons montré que le déclenchement calcique de la libération du neurotransmetteur s'accomplit par la liaison $\mathrm{du} \mathrm{Ca}^{2+}$ à Syt1 et à d'autres synaptotagmines, et que différentes isoformes de synaptotagmine jouent le rôle de senseur dans d'autres types d'exocytose $\mathrm{Ca}^{2+}$ dépendantes.

Après la description de Syt1, le premier défi était de tester si les domaines Syt1 C2 étaient bien un nouveau type de domaines de liaison entre le $\mathrm{Ca}^{2+}$ et les phospholipides. Nous avons montré que les domaines C2 de Syt1 se liaient aux phospholipides (Perin et al., 1990), que cette liaison était médiée par Syt1 purifiée à partir de cerveau, de manière $\mathrm{Ca}^{2+}$ dépendante (Brose et al., 1992) et qu'un seul des deux domaines C2 de Syt1 - le domaine $\mathrm{C} 2 \mathrm{~A}$ - replié de manière autonome liait le $\mathrm{Ca}^{2+}$ et les phospholipides en un complexe ternaire (Davetlof \& Südhof, 1993, 1994; figure 5B). De plus, les domaines $\mathrm{C} 2$ de Syt1 se lient également à la syntaxine 1 et aux complexes SNARE en présence de $\mathrm{Ca}^{2+}$ (Chapman et al., 1995; Li et al., 1995a, 1995b). En collaboration avec Steven Sprang et Josep Rizo, nous avons établi les structures atomiques des domaines C2 de Syt1 et défini l'architecture de leurs sites de liaison au $\mathrm{Ca}^{2+}$ (Sutton et al., 1995 : Shao et al., 1996, 1997; Ubach et al., 1998, 2001; Fernandez et al., 2001; figure 5A). Nos études structurales ont démontré que les domaines $\mathrm{C} 2$ de Syt1 sont composés de sandwiches $\beta$ avec des boucles souples émergeant du dessus et du dessous et que le $\mathrm{Ca}^{2+}$ se lie exclusivement aux boucles du dessus des domaines $\mathrm{C} 2$ dotés de sphères de coordination incomplètes (figures $5 \mathrm{~A}$ et $5 \mathrm{C}$ ). En conséquence, la liaison intrinsèque du $\mathrm{Ca}^{2+}$ à Syt1 a une affinité faible, mais est fortement renforcée par la liaison avec des phospholipides qui complètent les sphères de coordination (Davetlov et Südhof, 1993, 1994; Ubach et al., 1998; Fernandez et al., 2001).

La définition biochimique et structurale du domaine C2A de Syt1, comme module de liaison au $\mathrm{Ca}^{2+}$ replié de manière autonome - première description

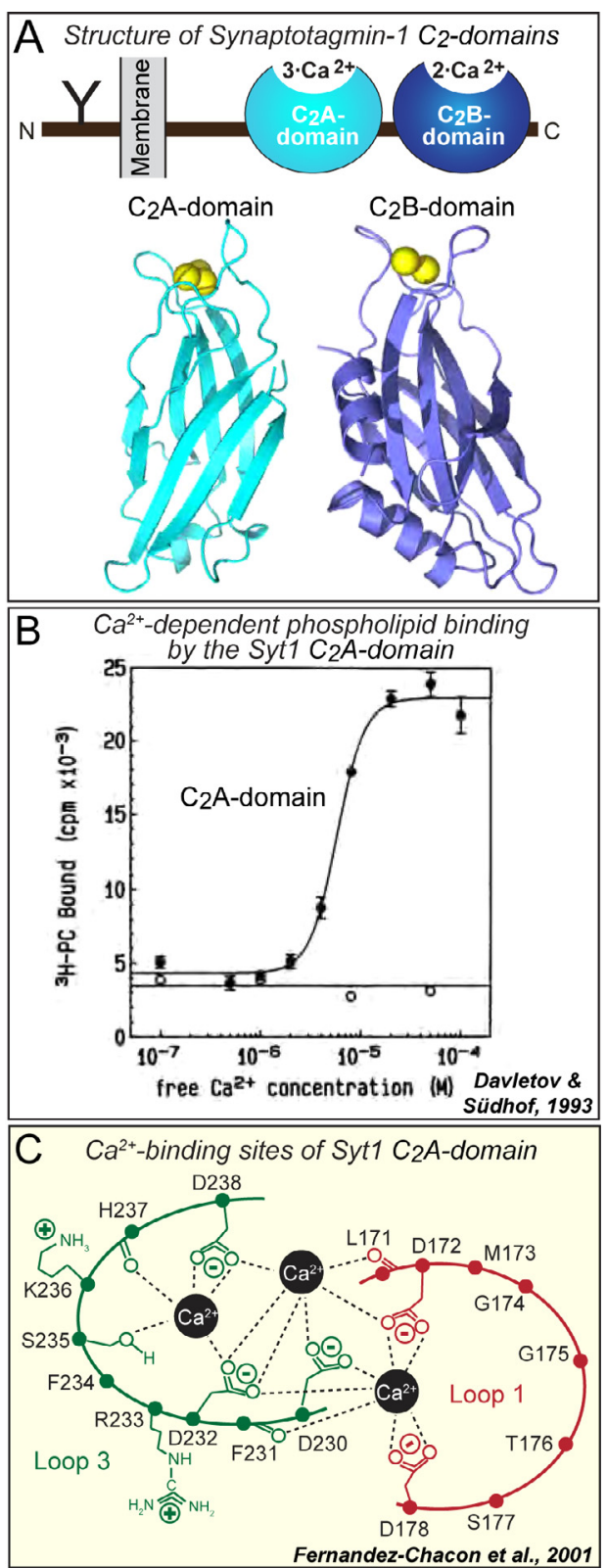

Fig. 5. Structure des domaines et liaison au calcium de la synaptotagmine-1. (A) Structure du domaine de la synaptotagmine-1 (Syt1) et structure des domaines C2 (courtoisie de J. Rizo; Shao et al., 1998; Fernandez et al., 2001). (B) Le domaine C2A de Syt1 et par extension d'autres domaines $\mathrm{C} 2$ sont des domaines de liaison au $\mathrm{Ca}^{2+}$, à repliement autonome. Les données illustrent la régulation à haute affinité et la forte coopérativité de la liaison des phospholipides au domaine C2A de Syt1 recombinant et purifié (reproduit de Davetlov \& Südhof, 1993). (C) Architecture des sites de liaison au $\mathrm{Ca}^{2+} \mathrm{du}$ domaine C2A de Syt1, déterminée par spectroscopie NMR (modifié de Fernández-Chacón et al., 2001). Notez que plusieurs ions $\mathrm{Ca}^{2+}$ sont reliés dans des sphères de coordination incomplètes par de multiples résidus aspartate qui se recouvrent. 
pour tout domaine $\mathrm{C} 2$ - se révéla être un paradigme valable pour tous les domaines $\mathrm{C} 2$, qui sont maintenant reconnus comme des motifs de liaison au $\mathrm{Ca}^{2+}$ de beaucoup de protéines (Rizo et Südhof, 1998; Corbalan-Garcia et Gomez-Fernandez, 2014). Toutefois, tous les domaines $\mathrm{C} 2$ ne lient pas le $\mathrm{Ca}^{2+}$. Certains domaines $\mathrm{C} 2$ sont des modules de liaison aux phospholipides $\mathrm{Ca}^{2+}$ indépendants (par exemple le domaine PTEN C2 ; Lee et al., 1999), tandis que d'autres sont des domaines d'interaction avec des protéines indépendantes du $\mathrm{Ca}^{2+}$ (par exemple le domaine $\mathrm{C} 2$ N-terminal de Munc13 qui lie les RIM, comme on le verra plus loin; Dulubova et al., 2005; Lu et al., 2006). Même les domaines $\mathrm{C} 2$ qui lient $\mathrm{Ca}^{2+}$ sont fonctionnellement divers. Par exemple, à la différence des domaines C2 de Syt1, certains domaines C2 présentent une forte affinité pour le $\mathrm{Ca}^{2+}$ même en l'absence de phospholipides (par exemple le domaine $\mathrm{C} 2$ central de Munc13 ; Shin et al., 2010). Les domaines C2 sont donc des modules protéiques versatiles qui sont le plus souvent des domaines de liaison aux phospholipides mais peuvent adopter de multiples autres fonctions.

\section{Démonstration que Syt1 est un senseur de $\mathrm{Ca}^{2+}$ pour l'exocytose}

Après que les études biochimiques ont établi que Syt1 liait le calcium, le défi suivant était de chercher si Syt1 était bien le senseur de $\mathrm{Ca}^{2+}$ théorisé depuis si longtemps par Katz pour expliquer la libération synaptique. Les études initiales chez C. elegans et la drosophile indiquaient de manière décevante qu'après la délétion de Syt1, une partie au moins de la libération de neurotransmetteur persistait malgré une réduction significative (DiAntonio et al., 1993; Littleton et al., 1993; Nonet et al., 1993). Nos analyses électrophysiologiques du knock out de Syt1 chez la souris, où des mesures à plus haute résolution de la libération étaient possibles, révélèrent alors que Syt1 est sélectivement et absolument requise pour la fusion synaptique synchrone rapide dans les neurones du cerveau antérieur, alors que d'autres formes, plus lentes, de libération induite par le $\mathrm{Ca}^{2+}$ peuvent s'en passer (figur 6; Geppert et al., 1994a; Maximov \& Südhof, 2005). Ces expériences, réalisées en collaboration avec Chuck Stevens à l'Institut Salk, expliquaient les phénotypes chez la drosophile et C. elegans, et établissaient que Syt1 est essentielle pour la libération déclenchée par le $\mathrm{Ca}^{2+}$, mais n'est pas indispensable pour la fusion elle-même - n'est même pas nécessaire pour toutes les fusions déclenchées par le $\mathrm{Ca}^{2+}$. De plus la délétion de Syt1 accroissait la «mini »-libération spontanée au niveau de certaines synapses, ce qui suggérait que Syt1 contribue normalement à bloquer l'exocytose spontanée des

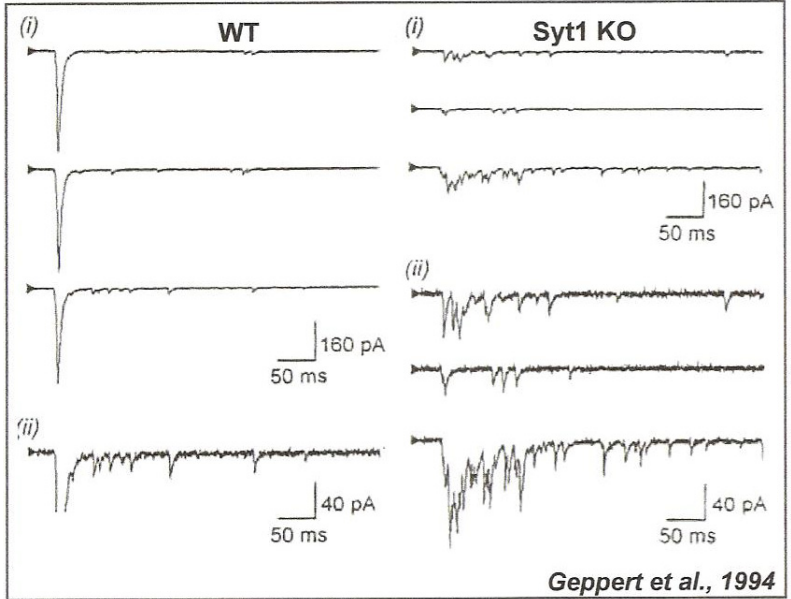

Fig. 6. Le KO de la synaptotagmine-1 (Syt1) supprime sélectivement le largage rapide synchrone du neurotransmetteur. Tracés des réponses synaptiques évoquées dans des neurones hippocampiques de souris nouvelles-nées sauvages (WT, à gauche) et Syt1 KO (à droite). Les réponses synaptiques ont été induites par des potentiels d'action isolés ; deux échelles différentes sont indiquées en (i) et (ii) (barres de calibration). Notez que le KO Syt1 supprime complètement la réponse synchrone rapide, mais pas les réponses asynchrones lentes. (Reproduit de Geppert et al., 1994a).

vésicules synaptiques (Maximov \& Südhof, 2005; Xu et al., 2009).

Les analyses du knock out de Syt1 étayaient donc l'hypothèse « de la synaptotagmine/senseur de $\mathrm{Ca}^{2+}$ », mais n'excluaient pas la possibilité que Syt1 positionne les vésicules à proximité des canaux $\mathrm{Ca}^{2+}$ voltage-dépendants (une fonction dont on sait maintenant qu'elle est le fait des RIM et des RIM-BP (Kaeser et al., 2011). Cette fonction de positionnement pourrait permettre à un autre « véritable » senseur calcique d'effectuer le déclenchement par le $\mathrm{Ca}^{2+}$. Cette hypothèse alternative, qui a été beaucoup discutée (Neher \& Penner, 1994), est en accord avec la libération résiduelle $\mathrm{Ca}^{2+}$-dépendante dans les synapses knock out pour Syt1, mais ne permet pas d'expliquer pourquoi Syt1 lie le $\mathrm{Ca}^{2+}$.

Pour tester directement si la liaison de $\mathrm{Ca}^{2+}$ à Syt1 déclenche effectivement la libération du neurotransmetteur, nous avons introduit une mutation ponctuelle (R233Q) dans le gène Syt1 endogène de la souris, qui diminuait de moitié l'affinité de liaison Syt1 $\mathrm{Ca}^{2+}$ pendant la liaison des phospholipides, mais n'avait pas d'effet détectable sur celle de la syntaxine- $1 \mathrm{Ca}^{2+}$ dépendante (figures $7 \mathrm{~A}$ et $7 \mathrm{~B}$; Fernández-Chacón et al., 2001). Des enregistrements électro-physiologiques, réalisés en collaboration avec Christian Rosenmund, ont révélé que la mutation R233Q convertissait la dépression synaptique pendant 


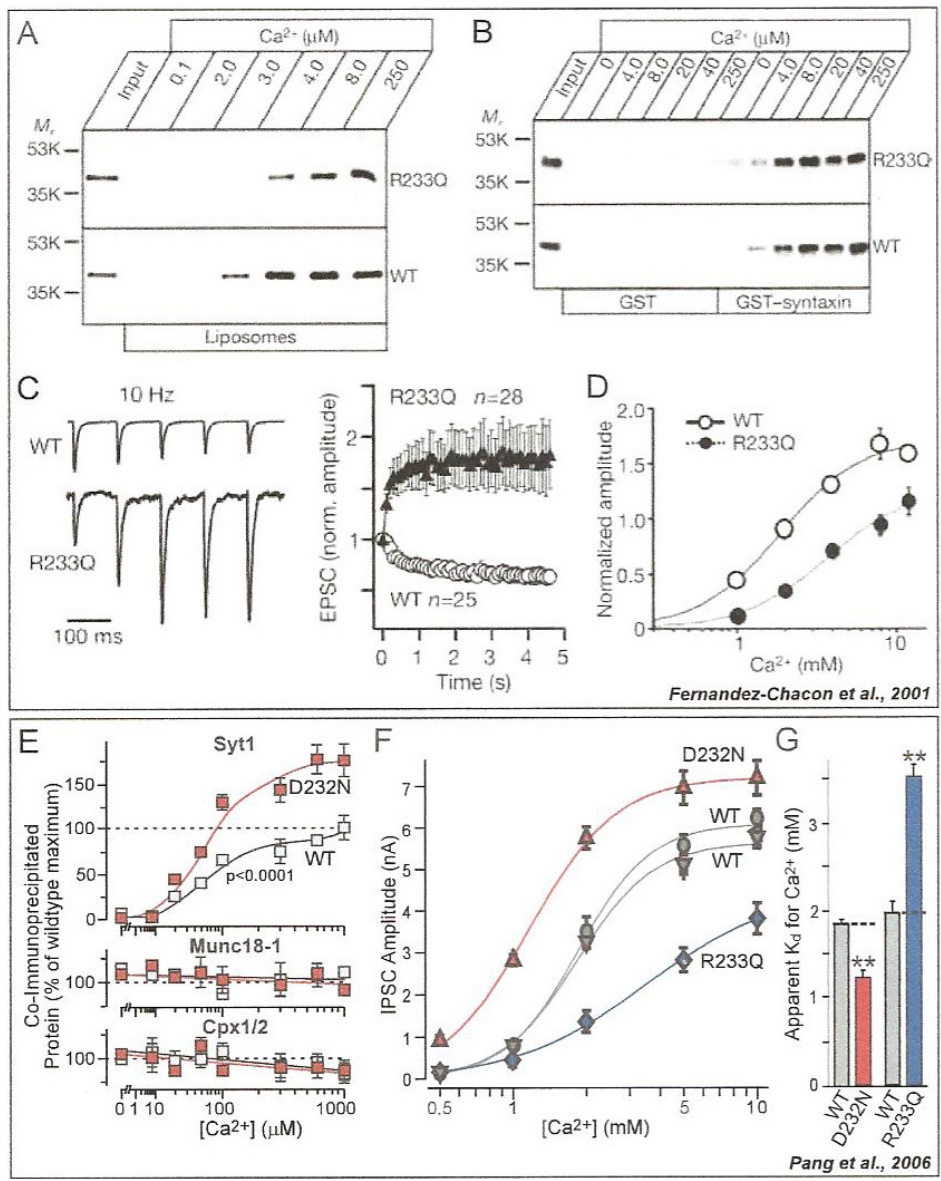

Fig. 7. La liaison du $\mathrm{Ca}^{2+}$ à la synaptotagmine-1 (Syt1) déclenche la libération de neurotransmetteur. Démonstration à l'aide de souris knock-in pourvues d'une mutation Syt1 à affinités pour le $\mathrm{Ca}^{2+}$ modifiées. A \& B. La substitution d'un seul aminoacide dans le domaine CA2 de Syt1 (R233Q) diminue l'affinité apparente de Syt1 pour le Ca ${ }^{2+}$, au cours de la liaison aux phospholipides mais pas au cours de la liaison à la syntaxine -1. Les données montrent des mesures de la liaison $\mathrm{Ca}^{2+}$-dépendante du domaine cytoplasmique de Syt1, sauvage ou mutante R233Q, à des liposomes (A) ou à la GST-syntaxine-1 immobilisée (B). C. La substitution R233Q d'un aminoacide diminue la probabilité de libération du neurotransmetteur, ce qui est mis en évidence par la conversion d'une dépression synaptique dans les synapses sauvages en une facilitation synaptique chez les mutants R233Q. Les réponses synaptiques sont mesurées pendant un train de stimulation de $10 \mathrm{~Hz}$ (à gauche, tracés représentatifs; à droite, réponses normalisées). D. La mutation R233Q diminue d'environ deux fois l'affinité apparente pour le $\mathrm{Ca}^{2+}$ pour le relargage du neurotransmetteur et pour la liaison aux phospholipides (voir A), ce qui explique la diminution de la probabilité de libération en C. Les données montrent les amplitudes normalisées des réponses synaptiques en fonction de la concentration en $\mathrm{Ca}^{2+}$ extracellulaire. E. Une autre substitution d'aminoacide dans le domaine C2A de Syt1 (D232N) a un effet distinct sur les propriétés de liaison au $\mathrm{Ca}^{2+}$ de Syt1 : elle accroît la liaison dépendante du $\mathrm{Ca}^{2+}$ de Syt1 aux complexes SNARE. Les données montrent les mesures de liaison dépendante du $\mathrm{Ca}^{2+}$ de Syt1 sauvage et de Syt1 mutée D232N aux complexes SNARE dans des homogénats de cerveau de souris knock in solubilisés au Triton X-100. Les complexes SNARE ont été immunoprécipités aux concentrations indiquées de $\mathrm{Ca}^{2+}$ libre, et les précipités ont été analysés par immunoblotting quantitatif pour Syt1 (courbes du haut), Munc18-1 et complexines (courbes du bas). Notons que Munc18-1 et les complexines co-précipitent constitutivement avec les complexes SNARE, alors que la co-immunoprécipitation de Syt1 est renforcée de manière spectaculaire aux concentrations croissantes de $\mathrm{Ca}^{2+} . \mathrm{F}$ et G. La comparaison directe des effets des mutations $k n o c k$ in D232N et R233Q de Syt1 démontre que ces deux mutations produisent des effets opposés sur l'affinité apparente pour le $\mathrm{Ca}^{2+}$ lors de la libération. F. Mesures de l'amplitude absolue des courants inhibiteurs post-synaptiques évoqués en fonction du $\mathrm{Ca}^{2+}$ extracellulaire dans des neurones en culture des souris mutantes knock in D232N ou R233Q et des souris sauvages (WT). Les amplitudes synaptiques répondent à une fonction de Hill. G. Affinité apparente pour le Ca ${ }^{2+}$ lors de la libération, calculée par adaptation pour la fonction de Hill des données de F, comparant les synapses des témoins sauvages aux synapses mutantes D232N ou R233Q. Les panneaux A-D ont été empruntés à Fernández-Chacón et al. (2001) ; les panneaux E-G à Pang et al. (2006), et à Xu et al. (2009). 
les trains de stimuli en une facilitation synaptique, compatible avec une probabilité de libération diminuée (figure $7 \mathrm{C}$ ).

Il est important que cette probabilité diminuée ait pu être attribuée à une division par 2 de l'affinité apparente pour le $\mathrm{Ca}^{2+}$ de la décharge du neurotransmetteur, ce qui prouvait formellement que Syt1 est le senseur de $\mathrm{Ca}^{2+}$ pour la libération.

Dans les études ultérieures, nous avons étendu cette analyse et introduit chez des souris knock out d'autres mutations ponctuelles, y compris une mutation (D232N) qui augmentait l'interaction $\mathrm{Ca}^{2+}$ dépendante de Syt1 avec les protéines SNARE (figure 7E; Pang et al., 2006a). Nous avons trouvé que cette mutation augmentait la libération de neurotransmetteur. Nous avons montré au cours d'une comparaison détaillée entre les mutations ponctuelles R233Q et D232N, qui diminue ou augmente respectivement l'affinité apparente Syt1/ $\mathrm{Ca}^{2+}$, qu'elles ont des effets correspondants opposés sur l'affinité $\mathrm{Ca}^{2+}$ apparente de la libération (figures $7 \mathrm{~F}$ et $7 \mathrm{G}$ ). De plus, dans des expériences parallèles sur des cellules chromaffines, réalisées en collaboration avec Erwin Neher, nous avons trouvé que Syt1 agit également comme un senseur calcique pour l'exocytose des granules endocrines (Voets et al., 2001 ; Sørensen et al., 2002), bien que, dans ce cas, la délétion de Syt1 ne cause qu'un affaiblissement minime de l'exocytose déclenchée par le $\mathrm{Ca}^{2+}$, parce que la fonction Syt1 est largement redondante avec celle de Syt7 dans les cellules chromaffines (Schonn et al., 2008; voir la discussion ci-dessous).

L'ensemble de ces travaux prouvent que Syt1 agit comme un senseur calcique pour l'exocytose vésiculaire. La question suivante était de déterminer si la liaison du $\mathrm{Ca}^{2+}$ aux deux domaines C2 de Syt1 contribuait au déclenchement de la libération. Les études initiales chez la drosophile avaient démontré que le domaine $\mathrm{C} 2 \mathrm{~B}$ était essentiel pour cette libération (Mackler \& Reist, 2001). Une autre étude suggérait que le domaine C2A était inutile (Robinson et al., 2002) mais le ratio signal/bruit de fond de ces expériences était trop faible pour écarter une contribution du domaine $\mathrm{C} 2 \mathrm{~A}$. Nous avons utilisé des expériences de «rescue » systématique pour comparer quantitativement l'activation calcique chez des mutants Syt1, privés des domaines C2A ou C2B. Nous avons montré que les domaines C2B et $\mathrm{C} 2 \mathrm{~A}$ contribuent tous deux significativement à la libération (Shin et al., 2009). De plus, nous avons observé qu'en l'absence du domaine $\mathrm{C} 2 \mathrm{~A}$, la libération calcium-dépendante avait une coopérativité calcique apparente significativement diminuée, démontrant ainsi que la liaison du $\mathrm{Ca}^{2+}$ au domaine $\mathrm{C} 2 \mathrm{~A}$ de la synaptotagmine-1 participe directement au déclenchement par le $\mathrm{Ca}^{2+}$ de la libération rapide.

\section{Diversité des synaptotagmines dans la libération rapide du neurotransmetteur déclenchée par $\mathrm{Ca}^{2+}$}

Le génome des mammifères code pour 16 synaptotagmines (définies comme des protéines à double domaine $\mathrm{C} 2$ avec une région $\mathrm{N}$-terminale transmembranaire). Les domaines C2 de 8 synaptotagmines (Syt-1-Syt3, Syt5-Syt7, Syt 9, et Syt 10) lient le $\mathrm{Ca}^{2+}$, tandis que ceux des 8 autres ne le font pas. Les 8 synaptotagmines liant le $\mathrm{Ca}^{2+}$ comprennent deux classes qui diffèrent en ce qu'elles ont (Syt 3, Syt5, Syt6 et Syt 10) ou pas (Syt1, Syt2, Syt7 et Syt9) une liaison disulfure terminale, permettant une dimérisation.

Lorsque la diversité des synaptotagmines a émergé (voir par exemple Geppert et al., 1991; Li et al., 1995a, 1995b), on a été surpris que le knock out de Syt1 ait produit un phénotype grave, alors que certaines au moins des autres synaptotagmines sont coexprimées avec Syt1. Toutefois, à l'aide d'expériences systématiques de restauration, nous avons montré que seules trois des huit synaptotagmines liant le $\mathrm{Ca}^{2+}$ Syt1, Syt2 et Syt 9 - interviennent dans l'exocytose rapide des vésicules synaptiques (Xu et al., 2007). Ces synaptotagmines présentent des cinétiques distinctes, avec Syt2 déclenchant la libération plus rapide, et Syt 9 plus lente que Syt1. La plupart des neurones du cerveau antérieur expriment seulement Syt1, expliquant le phénotype majeur du knock out de Syt1. Syt2 est le senseur calcique des synapses rapides du tronc cérébral et de la jonction neuromusculaire (Pang et al., 2006b, 2007; Sun et al., 2007; figures 8A et 8B), tandis que Syt9 est présente surtout dans le système limbique (Xu et al., 2007). Ainsi les propriétés cinétiques de Syt1, Syt2, et Syt9 correspondent aux besoins fonctionnels des synapses qui les contiennent.

Dans nos études initiales des KO de Syt1 (Geppert et al., 1994a), nous avions observé que, malgré la disparition de la libération synaptique rapide, une forme plus lente de libération calcium-dépendante persistait (figure 6). Nous avons donc cherché à définir sur le plan biochimique la contribution de la forme « rapide $»$ de libération dépendant de la synaptotagmine et à décrire les propriétés de la forme lente persistante. Pour ce faire, nous avons fait appel à la synapse du « calice de Held » comme système modèle, parce qu'elle permet le patch-clamp simultané des compartiments pré- et post-synaptiques, donnant une résolution sans équivalent pour des mesures électro-physiologiques (Forsythe, 1994; Borst \& Sakman, 1996). Cette synapse exprime seulement Syt2 parmi les synaptotagmines « rapides » (figure 8A; Sun et al., 2007). Chez le knock out de Syt2, la libération rapide de neurotransmetteur au niveau de la synapse du calice de Held est abolie; seule persistait une forme plus lente (figure 8B). Cette forme lente de libération n'était cependant pas facilitante lors de trains de stimuli à 


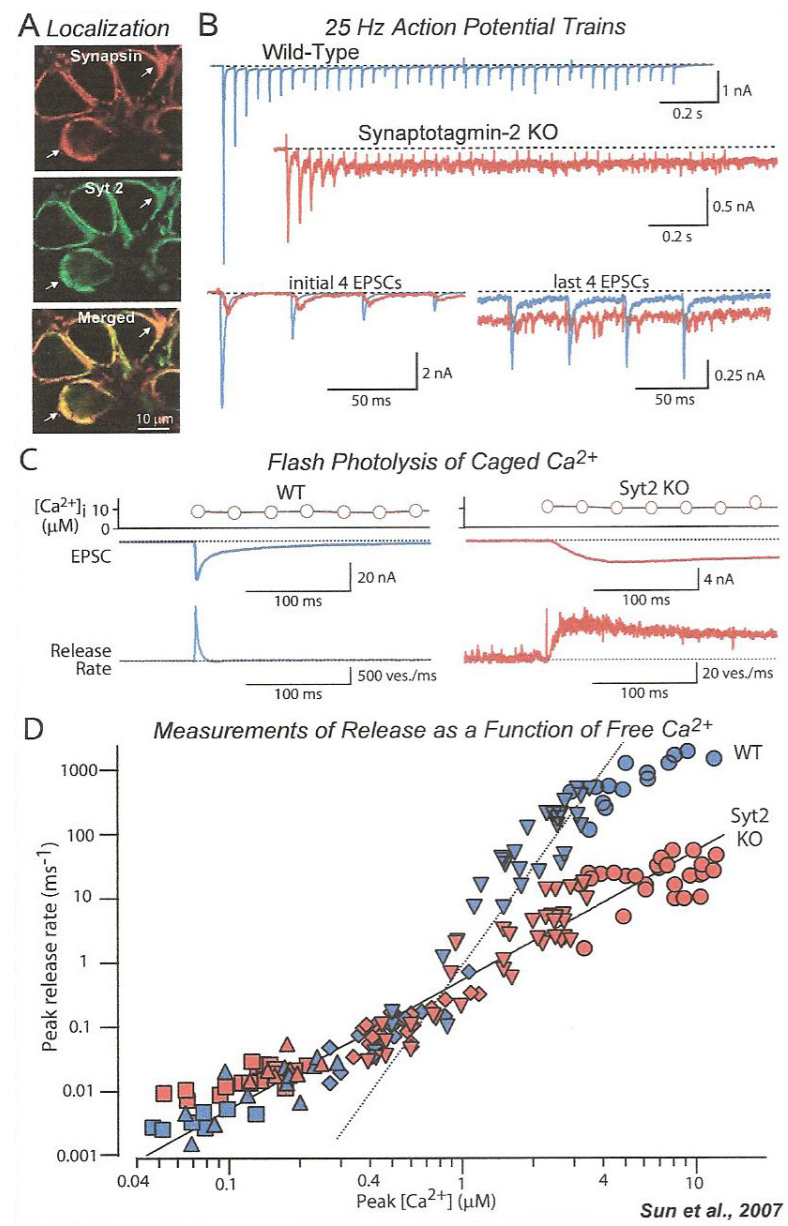

Fig. 8. La délétion de la synaptotagmine-2 (Syt2), le senseur calcique rapide de la libération au niveau de la synapse en Calice de Held, détecte une forme plus lente de la décharge déclenchée par $\mathrm{Ca}^{2+}$, qui est elle-même contrôlée par un senseur de $\mathrm{Ca}^{2+}$ secondaire, doté d'une coopérativité beaucoup plus faible que Syt2. A. La localisation de Syt2 par immunochimie démontre une expression abondante dans les terminaisons pré-synaptiques au niveau des synapses en Calice. B. Le knockout (KO) de Syt2 dans les synapses Calice supprime la plus grande partie de la décharge synchrone rapide induite par un train de potentiels à haute fréquence (40 stimuli à $25 \mathrm{~Hz}$ ). Les tracés représentatifs des réponses synaptiques (EPSC) enregistrés pendant la totalité du train sont montrés en haut (notez que les tracés sauvage et mutant sont à des échelles différentes), et les expansions des 4 ESPC initiales et finales en bas (notez ici que les tracés sauvage et mutant sont à la même échelle mais que ces échelles diffèrent pour le premier et les 4 derniers). Le déplacement de base des tracés du KO Syt2 reflète le déclampage du largage asynchrone, qui n'est pas observé dans les synapses sauvages. C. Le KO de Syt2 altère sévèrement la libération du neurotransmetteur déclenché par de fortes concentrations de $\mathrm{Ca}^{2+}$ dans $^{2}$ la synapse en Calice de Held. Les terminaisons pré-synaptiques ont été remplies (par une pipette à patch) avec du Ca ${ }^{2+}$ encagé qui peut être décagé par photolyse en flash. La quantité libérée a été mesurée au niveau post-synaptique en suivant l'ESPC, puis en calculant le nombre de vésicules libérées à un temps donné (taux de décharge). La concentration de Ca ${ }^{2+}$ pré-synaptique a été mesurée simultanément par microfluorométrie. D. La décharge de neurotransmetteur déclenchée par le $\mathrm{Ca}^{2+}$ montre une dépendance biphasique à la concentration en $\mathrm{Ca}^{2+}$ dans les synapses en Calice sauvages (WT) avec une coopérativité apparente basse au $\mathrm{Ca}^{2+}$ du largage (environ 2 ions $\mathrm{Ca}^{2+}$ ) à de faibles concentrations en $\mathrm{Ca}^{2+}$, et une coopérativité apparente élevée à des concentrations plus hautes (environ 5 ions $\mathrm{Ca}^{2+}$ ). Le KO de Syt2 abolit sélectivement la haute coopérativité du $\mathrm{Ca}^{2+}$ dans la phase de libération, faisant décroître les taux de largage d'environ 100 fois à des concentrations physiologiques de $\mathrm{Ca}^{2+}$, sans affecter significativement la décharge déclenchée par le $\mathrm{Ca}^{2+}$ à de faibles concentrations. Les graphiques résument les pics des taux de libération des ESPC en fonction de diverses concentrations en $\mathrm{Ca}^{2+}$ libre dans la terminaison présynaptique. La ligne pointillée représente une adaptation à la puissance 5 des données des terminaisons sauvages à $1 \mu \mathrm{M}$ de $\mathrm{Ca}^{2+}$ libre; la ligne pleine une fonction à la puissance 2 des données des terminaisons mutantes à toutes les concentrations de $\mathrm{Ca}^{2+}$. Notez que la ligne pleine est également valide pour les réponses de type sauvage à toutes les concentrations de $\mathrm{Ca}^{2+}$. Ces données sont adaptées de Sun et al. (2007). 
haute fréquence, à la différence de ce que nous avions observé dans les synapses Syt1 KO de neurones hippocampiques et corticaux (voir Maximov \& Südhof, 2005 et figure 9). En conséquence, le KO de Syt2 bloquait la plus grande partie de la libération calcium dépendante dans cette synapse, indépendamment de la fréquence de stimulation (Sun et al., 2007).

Nous avons ensuite analysé la dépendance au $\mathrm{Ca}^{2+}$ de la libération du neurotransmetteur, dans les synapses de calice de souris Syt2 KO en comparaison de souris sauvages, à l'aide de décageage localisé de $\mathrm{Ca}^{2+}$ par photolyse. Nous avons réalisé des mesures simultanées de la réponse post-synaptique (qui permet des calculs précis de l'exocytose des vésicules synaptiques) et des niveaux pré-synaptiques de $\mathrm{Ca}^{2+}$ par microflurométrie, une stratégie mise au point par les laboratoires de Sackmann, Schneggenburger et Neher (Bollmann et al., 2000; Schneggenbuger \& Neher, 2000). Conformément à une description antérieure (Bollmann et al., 2000), nous avons trouvé que la libération déclenchée par des concentrations physiologiques de $\mathrm{Ca}^{2+}$ montrait une coopérativité calcique apparente de 5, semblable au nombre d'ions $\mathrm{Ca}^{2+}$ liés aux synaptotagmines (figure $8 \mathrm{C}$ et $8 \mathrm{D}$ ). Toutefois la faible libération résiduelle déclenchée par le $\mathrm{Ca}^{2+}$ dans les synapses en calice des SYT2 KO présentait une coopérativité apparente de 2 seulement, ce qui suggérait que cette libération était médiée par un senseur calcique différent qui, au moins dans la synapse du calice de Held, avait des propriétés distinctes de celles de Syt1, Syt2, et Syt9 (Sun et al., 2007).

\section{Test de la fonction de la synaptotagmine 7 dans la libération lente induite par $\mathrm{Ca}^{2+}$}

Quel est le senseur calcique qui induit la libération résiduelle dans les synapses KO Syt1 et Syt2 et cette libération pourrait-elle être médiée par l'une des cinq autres synaptotagmines qui lient $\mathrm{Ca}^{2+}$ ? Cette libération résiduelle dans les neurones $\mathrm{KO}$ pour Syt1 montre des particularités selon les synapses. Alors que dans les synapses en calice de Held, la libération résiduelle des Syt2-KO reste faible et constante même aux fréquences de stimulation élevées (figure 8B), dans les synapses hippocampiques et corticales des Syt1$\mathrm{KO}$, la libération résiduelle « asynchrone » est massivement facilitée aux fréquences élevées (figure 9A). En conséquence, chez les Syt-KO, la quantité totale de libération calcique induite par des trains de stimuli à haute fréquence est voisine des synapses sauvages bien que le taux initial de libération rapide diffère d'un facteur plus grand que 10 (Maximov \& Südhof, 2005; Xu et al., 2012).

Avec l'objectif de définir le senseur calcique responsable de la libération résiduelle dans les neurones hippocampiques Syt1 déficients, nous nous sommes concentrés sur Syt7. Nous avions montré auparavant que Syt7, comme Syt1, fonctionne comme senseur de $\mathrm{Ca}^{2+}$ pour l'exocytose dans les cellules chromaffines et dans d'autres cellules neuroendocrines et endocrines (Sugita et al., 2001; Gustavsson et al., 2008, 2009; Schonn et al., 2008) et Paul Brehm avait mis en évidence un rôle de Syt7 à la jonction neuromusculaire (Wen et al., 2010). Nous avons trouvé que, alors que la perte de fonction de Syt7 ne produisait pas de changement majeur dans la libération de neurotransmetteur dans les neurones de type sauvage (Maximov et al., 2008), elle inhibait la plus grande part de la libération lente résiduelle déclenchée par le $\mathrm{Ca}^{2+}$ dans les neurones des mutants Syt1-KO (Bacaj et al., 2013; figure 9). Le phénotype perte-de-fonction Syt7 dans les neurones Syt1 -/- ne pouvait être compensé que par des sites de liaison à $\mathrm{Ca}^{2+}$ fonctionnels contenant Syt7, ce qui suggérait que Syt7 fonctionne comme un senseur calcique. À l'inverse de Syt1 chez lequel les sites de liaison calciques à domaine $\mathrm{C} 2 \mathrm{~B}$ étaient plus importants que les sites à domaine $\mathrm{C} 2 \mathrm{~A}$, chez le Syt7-KO, l'inhibition des domaines C2B n'avait aucun effet tandis que le blocage des sites de liaison calciques C2A abolissait son activité (Bacaj et al., 2013). Ce résultat indique que - de même que pour les autres synaptotagmines de sa classe (Syt1, Syt2 et Syt9) - les mécanismes d'action de Syt1 et Syt7 diffèrent partiellement.

Considérées dans leur ensemble, ces observations suggèrent que Syt7 fonctionne comme un senseur calcique de l'exocytose, (de même que Syt1, Syt2 et Syt9) mais avec une cinétique plus lente, sa fonction normale dans les synapses sauvages étant généralement masquée par la forme Syt1 plus rapide. Bien que la fonction de Syt7 ne soit pas immédiatement apparente dans la plupart des synapses normales (figure 9), des enregistrements appariés ont montré que Syt7 contribue physiologiquement à la libération pendant les trains de stimuli (Bacaj et al., 2013). Par conséquent ce sont quatre synaptotagmines (Syt1, Syt2, Syt7 et Syt9) qui, ensemble, sont responsables de presque toute la libération de neurotransmetteur à la synapse. La vitesse d'action différente de Syt1 et Syt7 est peutêtre liée à sa localisation car Syt7 n'a jamais été trouvée dans les vésicules synaptiques (Sugita et al., 2002; Maximov et al., 2008), alors qu'elle est présente sur les granules endocrines, ce qui suggère qu'elle est lente, parce qu'elle n'est pas aussi proche du site de la fusion déclenchée par $\mathrm{Ca}^{2+}$ que Syt1.

\section{Les complexines collaborent à la fusion dépendante de la synaptotagmine déclenchée par le $\mathrm{Ca}^{2+}$}

Nous avons identifié les complexines comme de petites protéines liées aux complexes SNARE mais pas aux protéines SNARE individuelles 


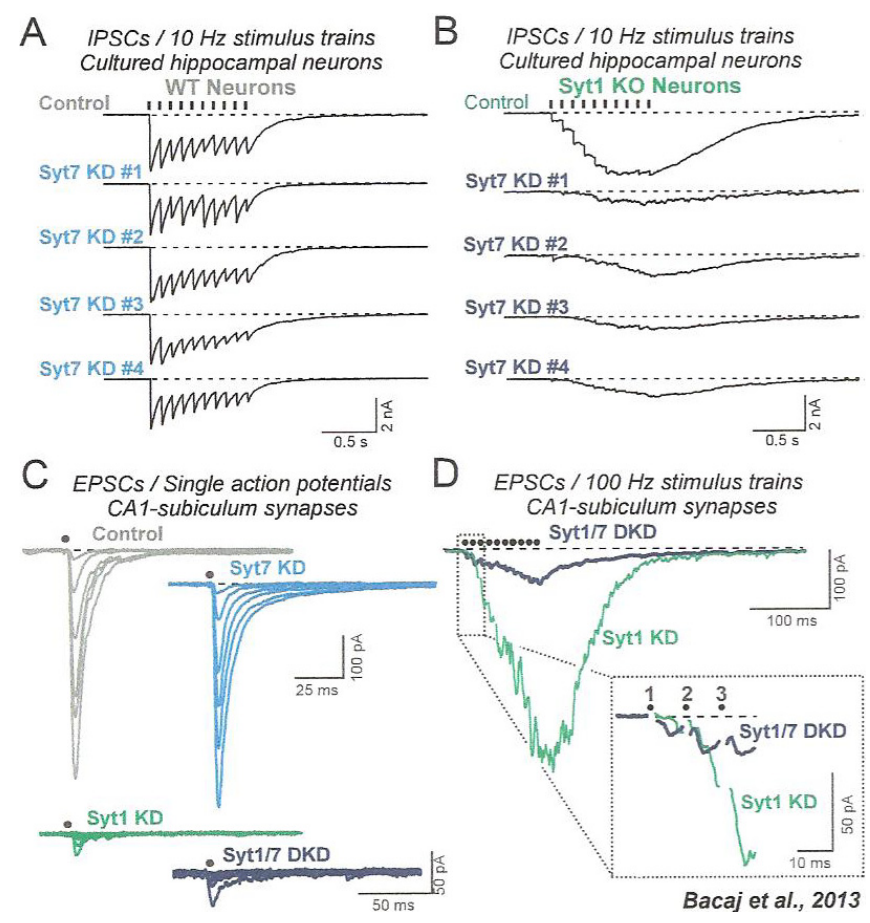

Fig. 9. Les knockdown de la synaptotagmine-7 (syt7) altèrent le largage résiduel lent des neurones knockout pour la synaptotagmine (Syt1). A et B. Dans des neurones hippocampiques en culture de type sauvage (WT), la suppression de l'expression de Syt7 par knockdown n'a pas d'effet sur la libération de neurotransmetteur évoquée par un train de stimuli à haute fréquence (A). Cependant la suppression de Syt7 dans les neurones également déficients en Syt1 (Syt1 KO) altère la plus grande partie de la libération calcium-dépendante lente qui persiste chez le Syt1 KO (B). Les données sont des tracés représentatifs d'EPSC évoqués par des trains de stimuli de $10 \mathrm{~Hz}$ obtenus soit dans des neurones témoins soit dans des neurones exprimant quatre shRNA différents de Syt7 (pour assurer la reproductibilité). Notez que dans les neurones hippocampiques, les trains de stimuli à haute fréquence induisent dans les neurones Syt1 KO une forme fortement facilitante de sortie asynchrone, telle que la quantité totale libérée pendant le train est similaire dans les neurones Syt1 $\mathrm{KO}$ et sauvages. A contrario, dans les synapses en Calice Syt2 KO, aucune facilitation de la décharge résiduelle n'est observée (voir figure 8B). C et D. Sur des tranches hippocampiques, la suppression de l'expression de Syt7, n'a pas, à elle seule, d'effet significatif sur la libération; cependant, comme dans les expériences in vitro, la suppression de l'expression de Syt1 supprime la phase initiale rapide de la libération mais une forme de décharge asynchrone, fortement facilitatrice, persiste, qui est sévèrement altérée par la suppression conjointe de Syt7. Les tracés montrent des EPSC évoqués par des stimuli isolés appliqués à intensités croissantes (C) ou par un train de stimuli de $100 \mathrm{~Hz}$ et 0,1 seconde. (D) Tracés représentatifs avec expansion de la réponse initiale, en bas. Les mesures ont été faites sur des tranches d'hippocampe de souris deux semaines après transfection de virus codant pour les shRNA contre différentes synaptotagmines au niveau du champ CA1 de l'hippocampe. Les ESPC ont été mesurés dans les neurones post-synaptiques du subiculum après stimulation des axones des neurones de la région CA1. Tous les résultats sont adaptés de Bacaj et al. (2013).

(McMahon et al., 1995; également caractérisées indépendamment plus tard par Ishizuka et al., 1995). La structure cristalline de la complexine liée au complexe SNARE, obtenue en collaboration avec Josep Rizo, a révélé que la complexine contient une hélice $\alpha$ centrale qui s'insère de manière antiparallèle dans le sillon formé par les motifs SNARE de la syntaxine 1 et la synaptobrévine 2 (Chen et al., 2002). L'hélice $\alpha$ centrale de la complexine est précédée en position N-terminale par une hélice $\alpha$ non structurée et suivie en position C-terminale par une séquence non structurée plus longue. L'analyse de neurones déficients en complexine montre que celle-ci est un cofacteur de la synaptotagmine, agissant à la fois pour clamper et activer la fusion calcium-dépendante (Reim et al., 2001; Tang et al., 2006; Huntwork \& Littleton, 2007 ; Maximov et al., 2009; Yang et al., 2010). L'absence de complexine produit un phénotype similaire à l'absence de Syt1 mais en moins sévère, avec une suppression partielle de l'exocytose synchrone rapide et une augmentation de l'exocytose spontanée, suggérant que les complexines et les synaptotagmines sont fonctionnellement interdépendantes.

Il y eut une certaine confusion à propos de la fonction de la complexine, parce que des tests de fusion in vitro suggéraient que la fonction essentielle 

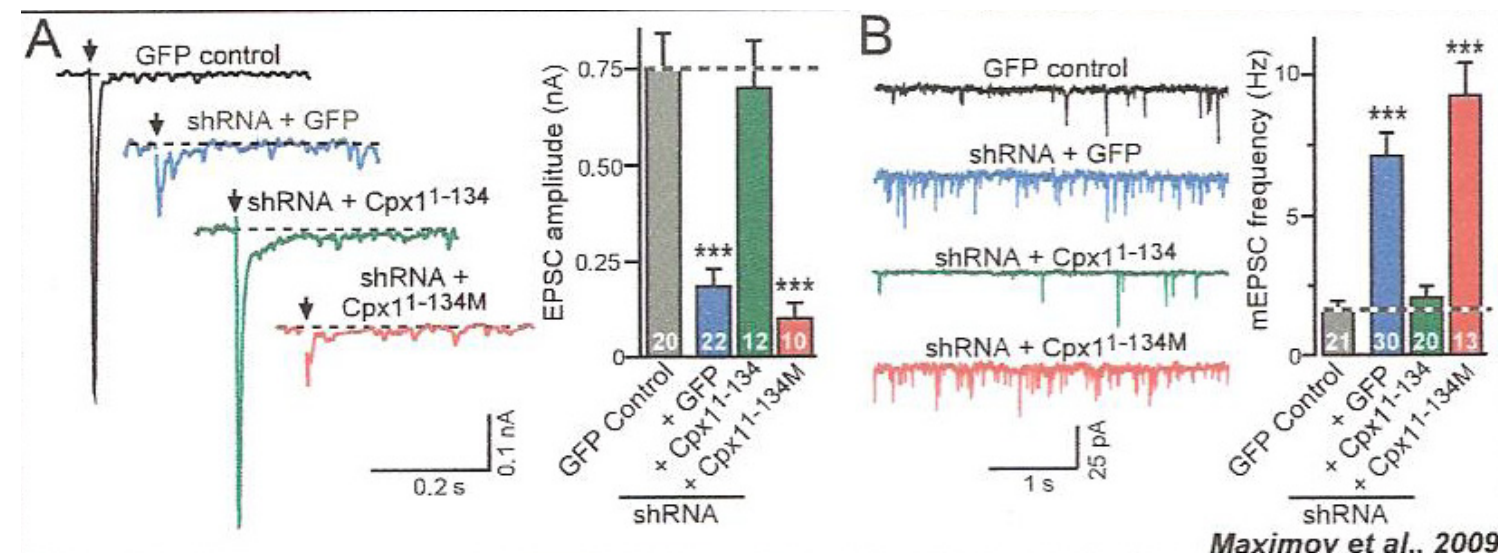

Fig. 10. La complexine fonctionne à la fois comme activateur et comme clamp de la fusion vésiculaire. A \& B. Les tracés montrent les courants post-synaptiques excitateurs (EPSC) induits par des potentiels d'action (A) et des EPSC miniatures spontanés (mEPSC) dans des neurones témoins, dans des neurones KO de la complexine, et dans des neurones $\mathrm{KO}$ avec co-expression de constructions pour la restauration de la complexine sauvage (Cpx1-134-) et de la complexine 1 mutée (Cpx1-134M) incapable de se lier aux complexes SNARE. Les tracés représentatifs sont à gauche et les graphiques qui les résument sont à droite pour illustrer la nature double de l'action de la complexine comme activateur de l'exocytose déclenchée par le $\mathrm{Ca}^{2+}$ (A) et comme clamp du mini-largage spontané (B). Les données sont adaptées de Maximov et al. (2009).

de la complexine était de clamper la fusion (Giraudo et al., 2006). D'un autre côté, l'analyse de la transmission synaptique dans des « autapses » (où des neurones isolés forment des synapses avec eux-mêmes, faute de meilleur partenaire), les complexines agissent seulement comme activateur de la fusion vésiculaire calcium-dépendante (Reim et al., 2001). Cependant, des études ultérieures sur des cultures de neurones dissociés permirent de révéler les deux activités de la complexine : la perte de fonction de la complexine provoquait un important accroissement des « mini » ou libération spontanée (interprétée comme un déclampage) et une altération majeure de la libération évoquée (interprétée comme un manque d'activation; Figure10) (Maximov et al., 2009).

Comment une petite molécule comme la complexine, composée de seulement 130 résidus, réussitelle à activer et à clamper des vésicules synaptiques pour permettre l'effet de la synaptotagmine? L'hélice $\alpha$ centrale, qui est liée au complexe SNARE, est essentielle à toute fonction de la complexine (figure 10; Maximov et al., 2009). L'hélice $\alpha$ accessoire n'est requise que pour le clampage mais non pour la fonction activatrice de la complexine, démontrant que le clampage lui-même n'est pas un pré-requis (Yang et al., 2010). La séquence N-terminale flexible de la complexine, en retour, intervient seulement dans l'activation mais non dans le clampage de la complexine (Xue et al., 2007; Maximov et al., 2009). Des résultats récents indiquent que la fonction d'activation de la complexine est extraordinairement complexe car cette molécule participe également à l'activation des vésicules synaptiques, mais que, pour cet aspect, c'est la séquence C-terminale qui est nécessaire (Yang et al., 2010 ; Kaeser-Woo et al., 2012).

Basé sur ces résultats, notre modèle actuel suppose que la liaison de la complexine aux SNARE active le complexe SNARE/protéines SM, et qu'au moins une partie de la complexine entre en compétition avec la synaptotagmine pour lier le complexe SNARE et clamper le complexe pour empêcher son assemblage définitif (Tang et al., 2006). La synaptotagmine activée par le $\mathrm{Ca}^{2+}$ déplace cette partie de la complexine, permettant ainsi l'ouverture du pore de fusion (figure 11). Toutefois, il est probable que la fonction de clampage de la complexine soit relativement moins importante que sa fonction d'activation. Bien qu'une augmentation d'un facteur 10 du taux de libération spontanée induit par la perte de fonction de la complexine soit significative, elle est très petite au niveau de synapses individuelles. Si l'on considère que chaque neurone reçoit des milliers de stimulations synaptiques, l'accroissement des mini-taux se traduit seulement par un événement de libération par synapse et par minute (Yang et al., 2013). De plus certaines isoformes de la complexine, exprimées en général à niveau faible (complexine-3 et -4) n'ont pas de fonction de clampage (Kaeser-Woo et al., 2012) et la fonction de la complexine dans l'exocytose déclenchée par $\mathrm{Ca}^{2+}$ des vésicules contenant de l'IGF-1 (voir ci-dessous) n'implique pas de clampage (Cao et al., 2013). Par conséquent, il est probable que la complexine fonctionne principalement comme un activateur d'exocytose, et que sa fonction de clampage est soit un 


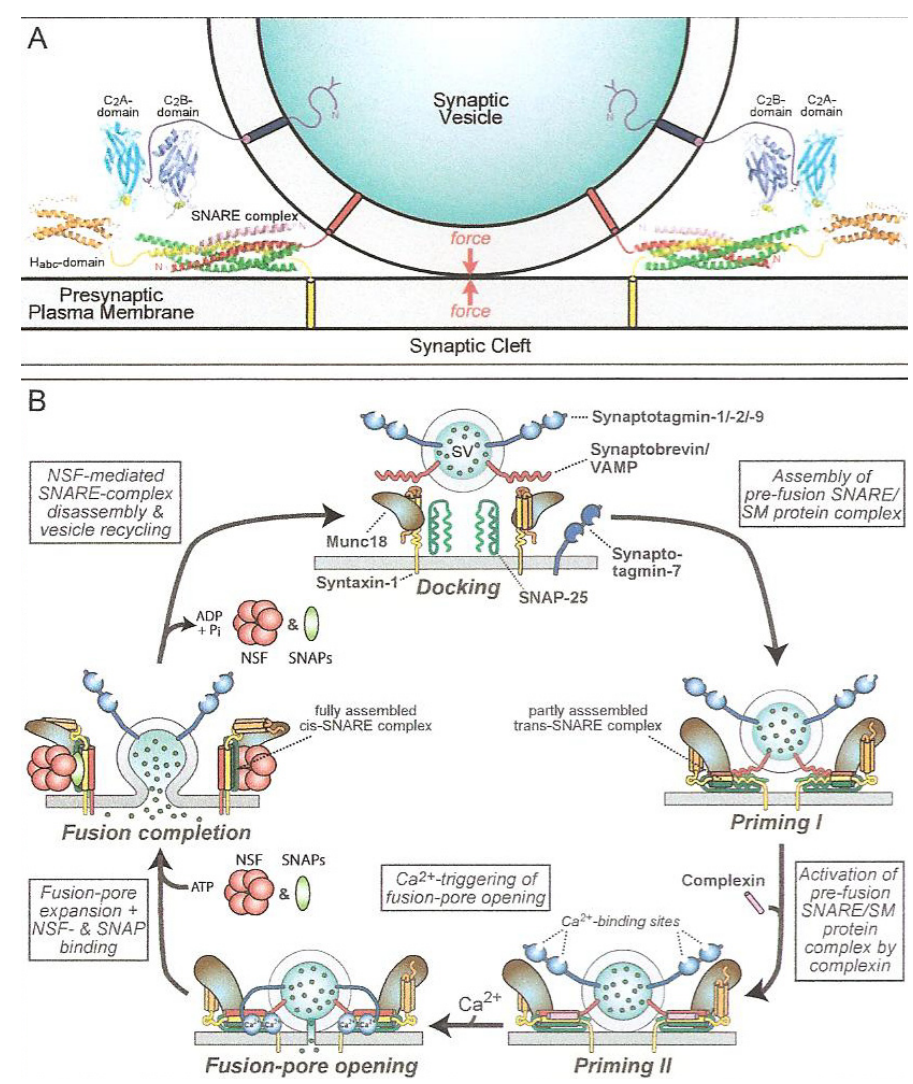

Fig. 11. Modèle de la collaboration des protéines SNARE et SM avec les synaptotagmines et les complexines pour la libération de neurotransmetteur déclenchée par le $\mathrm{Ca}^{2+} \mathrm{A}$. Structures atomiques des protéines SNARE, de la complexine et de Syt1 pendant la fusion des vésicules synaptiques. Ce schéma résume les structures atomiques obtenues en collaboration avec Josep Rizo (UT Southwestern) des domaines C2 de Syt1 (Shao et al., 1998; Fernandez et al., 2001), du domaine Habc de la syntaxine-1 (Fernandez et al., 1997) et du complexe SNARE assemblé contenant la complexine liée (en rose; Chen et al., 2002). Les régions transmembranaires sont schématisées par des cylindres et les séquences linker par des lignes. Toutes les structures sont à une échelle relative exacte par rapport aux vésicules synaptiques, montrant les contraintes spatiales de la collaboration entre Syt1 et l'assemblage complexe SNARE/complexine. Munc18-1 est également liée au complexe SNARE au même moment (voir figures 3D et 4) mais n'est pas montré car la structure de Munc18-1 liée au complexe SNARE n'est pas connue. La direction de la force produite par l'assemblage du complexe SNARE, qui déstabilise la surface de la membrane plasmique phospholipidique, est indiquée. B. Diagramme simplifié de l'action des synaptotagmines et des complexines dans le cycle protéique SNARE/SM. Ce cycle comprend l'assemblage des protéines SNARE, synaptobrévines/VAMP, SNAP25 et syntaxine-1 en complexes, dont la formation complète force l'ouverture du pore de fusion; la protéine SM Munc 18-1 reste associée à la syntaxine-1 tout au long du cycle et est essentielle à l'ouverture du pore. Après la fusion, l'ATPase chaperonne NSF et ses adaptateurs SNAP catalysent la dissociation du complexe SNARE. La complexine se lie pour assembler partiellement les complexes SNARE pendant l'activation et sert d'adaptateur essentiel qui permet à la synaptotagmine d'agir comme senseur calcique pour déclencher l'ouverture du pore de fusion (dernière ligne du cycle). Notez qu'il est possible que la synaptotagmine interagisse de manière constitutive avec le complexe protéines SM/SNARE de manière $\mathrm{Ca}^{2+}$ indépendante pour former un complexe de fusion unique avant le déclenchement par le $\mathrm{Ca}^{2+}$ de l'exocytose, et que le $\mathrm{Ca}^{2+}$ ne provoque pas une fusion tout-ou-rien de la synaptotagmine au complexe SNARE, comme il le fait pour la liaison de la synaptotagmine aux phospholipides, mais en revanche il détermine un réarrangement du complexe de pré-fusion. Ceci n'est pas montré dans le diagramme, à cause des difficultés à représenter ces interactions tridimensionnelles multiples dans un format bidimensionnel. De plus, les synaptotagmines et les complexines clampent toutes deux le largage spontané, probablement via leur liaison constitutive, indépendante du $\mathrm{Ca}^{2+}$, aux complexes SNARE partiellement assemblés. Trois synaptotagmines vésiculaires agissent comme senseurs calciques pour l'exocytose rapide (Syt1, Syt2, Syt9). Enfin, Syt7, qui n'est pas présente dans les vésicules synaptiques mais se localise probablement dans la membrane plasmique pré-synaptique (Sugita et al., 2001) est responsable de formes plus lentes d'exocytose déclenchée par le $\mathrm{Ca}^{2+}$ (Sy7 n'est montrée que dans le schéma du haut pour simplifier). Le dessin est adapté de Südhof (2013a). 
épiphénomène, soit une activité mineure de régulation fine de la transmission synaptique.

\section{Comment SNARE et les protéines SM collaborent avec les synaptotagmines et les complexines pour la fusion déclenchée par $\mathrm{Ca}^{2+}$}

La convergence des études biochimiques et biophysiques sur la machinerie de libération des neurotransmetteurs nous a conduits à proposer un modèle préliminaire (figure 11).

Schématiser à l'échelle les structures atomiques des protéines SNARE, de la complexine et de la synaptotagmine dans le contexte d'une vésicule synaptique arrimée et activée fait apparaître un espace encombré, dans lequel tous les partenaires sont très proches, et permettent des interactions rapides (figure 11). Si nous considérons comment des interactions séquentielles des protéines SNARE et SM avec la complexine et la synaptotagmine peuvent réaliser la fusion déclenchée par le $\mathrm{Ca}^{2+}$, le modèle le plus plausible est que la complexine et la synaptotagmine agissent en plus des deux changements conformationnels séquentiels majeurs impliqués dans l'assemblage du complexe protéique SNARE/SM (figure 11B ; voir aussi figure 4). Spécifiquement, une fois que les vésicules ancrées et arrimées sont activées pour la fusion par l'ouverture de la conformation fermée de la syntaxine-1 et par l'assemblage partiel du complexe trans-SNARE (activation I, figure 11B), la complexine se lie à ce complexe partiel pour le «superactiver $»$ et fournir aux vésicules l'énergie nécessaire à la fusion déclenchée par le $\mathrm{Ca}^{2+}$ (activation II). Il est probable que les synaptotagmines se lient aussi constitutivement aux complexes SNARE en voie d'assemblage indépendamment du $\mathrm{Ca}^{2+}$, et la liaison à la complexine et à la synaptotagmine contribue peut être à geler le complexe partiellement assemblé et, de cette manière, à le clamper. Le $\mathrm{Ca}^{2+}$ déclenche alors l'ouverture du pore de fusion en se liant à la synaptotagmine, qui à son tour se lie aux phospholipides et change son interaction avec le complexe trans-SNARE pour déplacer en partie la complexine. Il est probable que la complexine et la synaptotagmine interagissent constitutivement avec le complexe des protéines SNARE/SM d'une manière indépendante du $\mathrm{Ca}^{2+}$ pour former un complexe pré-fusionnel unique, et que le $\mathrm{Ca}^{2+}$ n'induit pas une liaison tout-ou-rien de la synaptotagmine au complexe SNARE comme il le fait pour la synaptotagmine aux phospholipides, mais qu'il provoque plutôt un réarrangement du complexe pré-fusionnel (voir par exemple Shin et al., 2003).

Le mécanisme le plus simple par lequel la liaison du $\mathrm{Ca}^{2+}$ à la synaptotagmine pourrait ouvrir le pore de fusion serait d'exercer une traction sur le complexe protéique SNARE/SM, une traction qui pourrait être déclenchée par la liaison de la synaptotagmine aux phospholipides induite par le $\mathrm{Ca}^{2+}$. Après l'ouverture du pore de fusion, celui-ci se dilate, et NSF et les SNAP sont recrutés par le complexe cis-SNARE assemblé. NSF dissocie ensuite le complexe cis-SNARE, le complexe Munc-18-1/SNARE assemblé est transformé en complexe Munc18-1/syntaxine hétéromérique, et les vésicules synaptiques se recyclent par l'une ou l'autre des diverses formes d'endocytose (voir figure 1).

\section{Voies parallèles d'exocytose médiée par la synaptotagmine et déclenchée par $\mathrm{Ca}^{2+}$}

Les quatre synaptotagmines dépourvues de groupes disulfure N-terminaux (Syt1, Syt2, Syt7, Syt9) sont actives dans l'exocytose synaptique et neuroendocrine, mais qu'en est-il des quatre autres qui sont des dimères liés par des ponts disulfures? Des études récentes ont révélé que l'une de celles-ci, Syt10, agit aussi comme un senseur de $\mathrm{Ca}^{2+}$ dans l'exocytose, mais dans une forme d'exocytose qui diffère de celle de la synapse et du granule neuroendocrine. Plus précisément, nous avons trouvé que Syt10 fonctionnait dans les neurones olfactifs comme senseur calcique pour des vésicules spécialisées contenant de l'IGF-1 (Cao et al., 2011). Ces vésicules diffèrent des vésicules à neuropeptides présentes dans les mêmes neurones (ces dernières ressemblent plus à des granules neuroendocrines et contiennent Syt1; Cao et al., 2013). Ces expériences démontrent qu'à l'échelle d'un neurone unique, différentes synaptotagmines interviennent pour des réactions distinctes de fusion déclenchées par le $\mathrm{Ca}^{2+}$ (figure 12). De plus, ces observations indiquent que l'exocytose déclenchée par le $\mathrm{Ca}^{2+}$ dépend en général de senseurs calciques à synaptotagmines et que les différentes synaptotagmines contribuent à la spécificité et aux propriétés différentielles de voies d'exocytose.

De manière intéressante, la complexine participe non seulement à l'activité des synaptotagmines dans la libération des neurotransmetteurs, mais aussi à celle de Syt10 dans la sécrétion d'IGF1, malgré les structures covalentes différentes de Syt1 et Syt10 (Cao et al., 2013). Il est donc vraisemblable que la complexine est un cofacteur général pour toutes les synaptotagmines dans l'exocytose régulée. Cette hypothèse est étayée par le fait que la complexine a une distribution ubiquitaire dans toutes les cellules (McMahon et al., 1995), et qu'elle est également au centre de l'insertion post-synaptique des récepteurs de type AMPA glutamate pendant la LTP (Long Term Potentiation) (Ahmad et al., 2012), suggérant que les complexines sont des cofacteurs généraux pour l'exocytose régulée. 


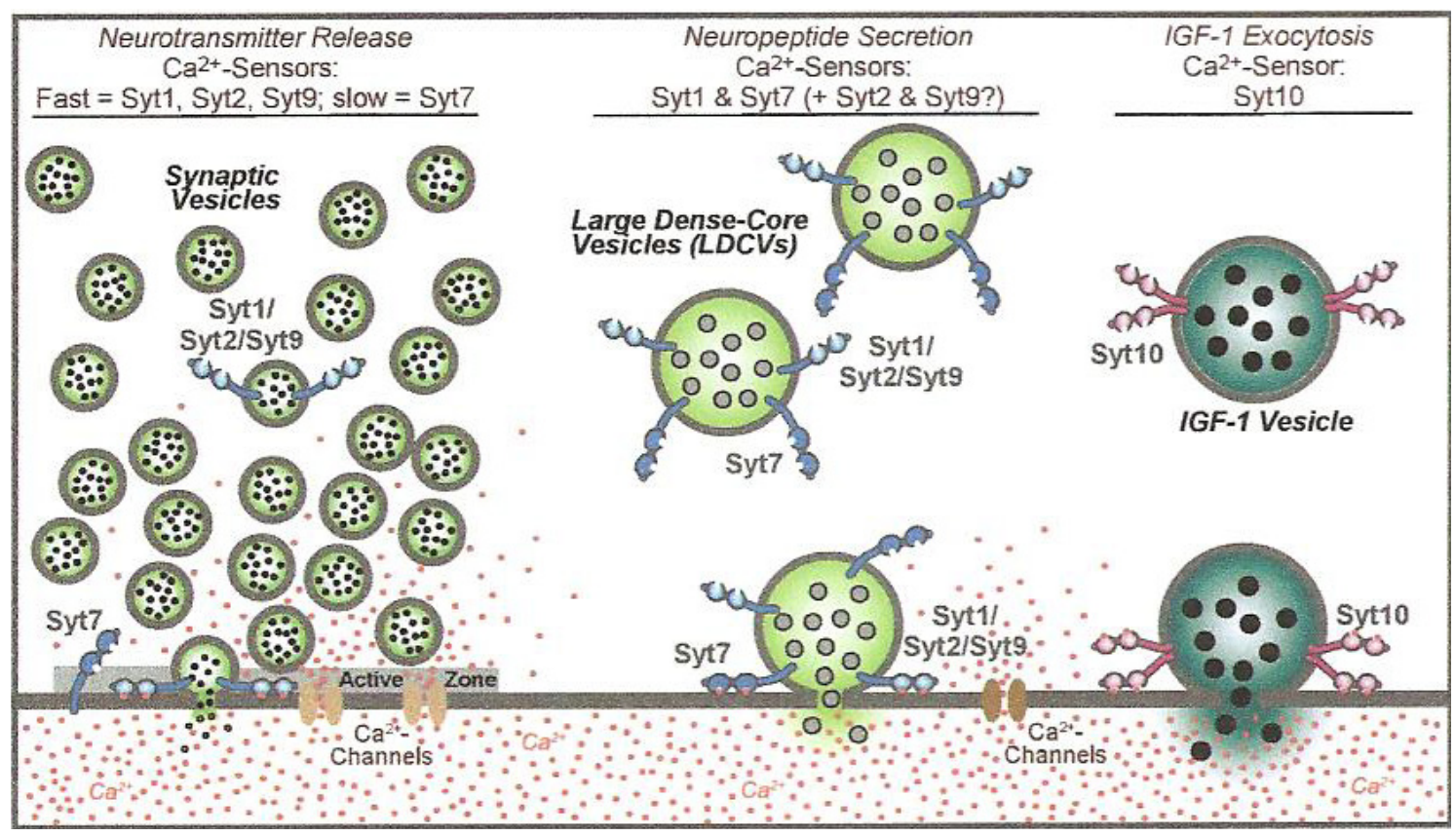

Fig. 12. Fonctions chevauchantes et non chevauchantes des différentes synaptotagmines dans le déclenchement de divers types d'exocytose par le $\mathrm{Ca}^{2+}$ dans un neurone. Trois types d'exocytose déclenchées par le $\mathrm{Ca}^{2+}$ sont illustrés : à gauche, exocytose des vésicules synaptiques responsables de la libération des neurotransmetteurs via Syt1, Syt2 et/ou Syt9 comme senseurs calciques rapides (Xu et al., 2007) et Syt7 comme senseur calcique lent (Bacaj et al., 2013). Au centre, l'exocytose des grandes vésicules à cœur dense (LDCV), qui utilise les mêmes senseurs que l'exocytose des vésicules synaptiques (Syt1 et Syt7), d'après des travaux sur les cellules chromaffines (Sugita et al., 2001; Schonn et al., 2007) et probablement aussi Syt2 et Syt9. À droite, l'exocytose d'une classe distincte de vésicules peptidergiques plus grandes que les LDCV et qui utilisent Syt10 comme senseur calcique (Cao et al., 2011 et 2013). Notez que, bien que Syt7 ait été montrée capable d'opérer aussi bien dans l'exocytose des vésicules synaptiques que dans celle des LCDV, elle est absente des vésicules synaptiques mais présente sur les LCDV; on pense qu'elle agit plus lentement dans la décharge des neurotransmetteurs à cause de sa localisation différente. Le diagramme est adapté de Cao et al. (2011).

\section{Organisation de la machinerie de libération dans la zone active}

Dans une terminaison pré-synaptique, les vésicules s'ancrent et fusionnent dans la zone active de la membrane plasmique pré-synaptique. La zone active est une aire spécialisée qui apparaît dense aux électrons en ultrastructure; cette zone est localisée précisément en face des groupes de récepteurs post-synaptiques (figure 1). La première protéine de zone active que nous ayons identifiée est Munc13-1 (Brose et al., 1995), nommée d'après Munc18-1 (bien qu'elle n'ait aucune relation) et d'après un gène homologue de C. elegans (unc13), essentiel pour la coordination des mouvements du ver mais dont la fonction reste inconnue (Brenner, 1974). Sur la base de cette homologie, du phénotype « incoordiné $»$ du ver, et de sa localisation à la zone active, nous avons supposé que Munc131 pourrait être un composant de la machinerie de libération du neurotransmetteur (Brose et al., 1995). Cette hypothèse a été confirmée par l'analyse de synapses KO privées de Munc13-1, qui présentaient une disparition spectaculaire de l'activation des vésicules synaptiques (Augustin et al., 1999).

Immédiatement après Munc13-1, nous avons identifié une série d'autres protéines de la zone active, comme CASK (Hata et al., 1996), les RIM (Wang et al., 2000) et les ELK (Wang et al., 2002; voir aussi Ohtsuka et al., 2002), tandis que d'autres chercheurs en identifiaient plusieurs encore comme les $\alpha$ liprines (Zhen \& Jin, 1999), bassoon (tom Dieck et al., 1998) et piccolo (Wang et al., 1999; Fenster et al., 2000). De manière intéressante, la plupart de ces protéines se lient directement ou indirectement les unes aux autres, formant un réseau dans la zone active (Südhof, 2012). Plus précisément, les RIM se lient à Munc13-1, aux RIM-BP, aux ELK (il n'est pas clair que cette dernière liaison soit importante du point de vue physiologique) et aux $\alpha$ liprines, ce qui suggère que les RIM sont le pivot central du réseau, et que d'autres interactions relient certaines des autres protéines entre elles (Wang et al., 2000, 2003; Betz et al., 2001; Schoch et al., 2002). Il est évident que beaucoup de questions sont encore 
ouvertes à propos de la zone active, les plus importantes concernant les mécanismes qui la positionnent précisément en face d'une spécialisation postsynaptique. Néanmoins, nous avons maintenant une vue plausible de la manière dont la zone active accomplit ses trois fonctions, c'est à dire l'ancrage des vésicules synaptiques à la membrane plasmique, l'activation de ces vésicules pour la fusion et le recrutement des canaux $\mathrm{Ca}^{2+}$ à proximité des vésicules ancrées et activées.

\section{Ancrage des vésicules synaptiques dans la zone active}

Comme dans d'autres processus de trafic membranaire, l'arrimage des vésicules synaptiques implique des protéines Rab, petites GTPases qui sont lointainement apparentées aux protéines ras. Le rôle central des protéines Rab dans le trafic membranaire a été découvert par Novick au cours des études sur Sec4p (Salminen \& Novick, 1987). Poursuivant ce travail, nous avons observé en 1992 en collaboration avec Reinhard Jahn que Rab3, la protéine Rab la plus abondante du cerveau, est fortement enrichie dans les vésicules synaptiques au repos, mais se dissocie des vésicules pendant l'exocytose, ce qui suggérait un rôle dans la libération du neurotransmetteur (von Mollard et al., 1990, 1991). Ultérieurement des analyses génétiques chez la souris des quatre isoformes de Rab3 (Rab3A, 3B, 3C et 3D) confirmèrent que Rab3 jouait un rôle central dans la libération vésiculaire (Geppert et al., 1994b; Schlüter et al., 2004, 2006). De plus, des isoformes de Rab3 isolées accomplissaient par elles-mêmes des fonctions essentielles; en effet des délétions de Rab3A ou de Rab3B provoquaient des changements distincts des formes de plasticité pré-synaptique à court et long terme (Geppert et al., 1994b; Schlüter et al., 2004, 2006; Tsetenis et al., 2011).

Dans notre recherche d'un mécanisme d'action des Rab3, nous avions initialement testé le rôle fonctionnel de la rabphiline, le premier effecteur supposé de Rab3 identifié par Yoshimi Takai (Shirataki et al., 1993). Cependant, les délétions de la rabphiline ne produisaient que des modifications mineures de la libération, suggérant que cette molécule ne jouait qu'un rôle secondaire (Schlüter et al., 1999; Deak et al., 2006).

Nous avons alors recherché des protéines effectrices de Rab3 supplémentaires, définies par une liaison dépendante du GTP à Rab3 mais pas aux autres Rab majeures. Nous avons identifié les RIM (pour «Rab3-Interacting Molecules »), une famille de grandes protéines de la zone active contenant des multi-domaines, évolutivement conservées (Wang et al., 1997, 2000). Chez les mammifères, quatre gènes apparentées aux RIM sont exprimés, parmi lesquels deux seulement (les RIMs1 et RIMs2) produisent des protéines qui contiennent le domaine de liaison à Rab3 (Wang et al., 2000, 2002). Les gènes RIMs1 et RIMs2, comportent de multiples promoteurs indépendants, codant pour cinq formes principales $(\operatorname{RIM} 1 \alpha, \operatorname{RIM} 1 \beta$, RIM $2 \alpha$, RIM $2 \beta$ et RIM2 $\gamma$ ) qui sont encore diversifiées par un épissage alternatif extensif.

Des travaux ultérieurs, poursuivis pendant 15 ans, ont révélé que les RIM remplissent de multiples fonctions dans la zone active, fonctions qui s'étendent bien au-delà de leur rôle comme effectrices de Rab3. Comme nous le verrons plus loin, les RIM sont cruciales, non seulement pour arrimer/ancrer les vésicules synaptiques, mais aussi pour recruter les canaux calciques dans la zone active, pour conférer la plasticité pré-synaptique à court et long terme, et pour mettre en route la fonction activatrice des protéines Munc13. En ce qui concerne la fonction d'arrimage/ancrage des RIM, suggérée par leur localisation dans la zone active et leur capacité de liaison à Rab3, cette fonction avait été validée en premier lieu chez $C$. elegans, qui n'a qu'un seul gène RIM (désigné unc10) (Koushika et al., 2001 ; Gracheva et al., 2008). Toutefois, chez la souris, les délétions d'isoformes isolées de RIM, y compris celle de la forme prédominante $\operatorname{RIM} 1 \alpha$, n'altéraient pas de manière détectable l'ancrage des vésicules, analysée par microscopie électronique (Schoch et al., 2002) alors que des KO conditionnels doubles, qui supprimaient toutes les isoformes codées par les gènes RIMs1 et RIMs2, présentaient une réduction massive de l'ancrage des vésicules synaptiques (Han et al., 2011; Kaeser et al., 2011). Ces études suggèrent que les vésicules synaptiques sont arrimées («ancrées ») aux zones actives via une liaison dépendant du GTP entre des protéines RIM de la zone active et des protéines Rab3/27 des vésicules synaptiques.

Il faut noter qu'hormis les RIM, aucune des protéines analysées ne sont apparues indispensables à l'arrimage des vésicules synaptiques, lors d'analyses traditionnelles de microscope électronique sur des coupes de tissus fixés. Toutefois, une image complètement différente a été obtenue lorsque la microscopie électronique est mise en œuvre sur des tissus non fixés, rapidement congelés - un grand nombre de gènes additionnels ont été alors reconnus comme essentiels pour l'arrimage. Dans de telles préparations, même le KO simple de RIM1 $\alpha$ provoque un phénotype de défaut d'arrimage. Pourtant, il est peu probable que tant de protéines ancrent les vésicules sans redondance, et ces phénotypes pourraient davantage refléter des défauts d'activation que d'arrimage. Ainsi, alors que de multiples molécules peuvent contribuer à l'attachement stable des vésicules synaptiques à la zone active, seules les RIM semblent vraiment requises pour l'ancrage. Il faut aussi noter que l'ancrage des granules neurosécrétoires dans les cellules chromaffines 
se comporte différemment de celui des vésicules synaptiques à la zone active. Par exemple, le KO Syt1 bloque l'ancrage des granules sécrétoires (de Wit et al., 2009), mais pas celui des vésicules synaptiques (Geppert et al., 1994b). Toutefois, le KO Syt1 n'a qu'un effet marginal sur l'exocytose déclenchée par le $\mathrm{Ca}^{2+}$ dans les cellules chromaffines, contrairement à son effet sur l'exocytose synaptique, probablement parce que Syt1 est redondant avec Syt7 pour l'exocytose des granules chromaffines (Xu et al., 2007; Schonn et al., 2008). Cette divergence entre ancrage et exocytose suggère que, à la différence des synapses, l'ancrage n'est peutêtre pas essentiel pour l'exocytose dans les cellules chromaffines.

\section{Activation des vésicules pour la fusion}

On pense que l'activation transfère les vésicules dans un pool de vésicules facilement libérables (ReadilyReleasable Pool, RRP), qui sont alors compétentes pour la fusion déclenchée par le $\mathrm{Ca}^{2+}$. Un grand nombre de protéines ont été impliquées dans l'activation. En plus des protéines actives dans la fusion elle-même (c'est à dire les protéines SNARE et SM) et de la complexine, les facteurs d'activation les plus importants sont probablement Munc13 et les RIM qui se lient les unes aux autres.

Des analyses largement menées dans les laboratoires de Nils Brose et de Josep Rizo ont révélé que la protéine Munc13 est essentielle à l'activation des vésicules, probablement parce qu'elle catalyse l'assemblage du complexe SNARE via son domaine MUN (Augustin et al., 1999; Varoqueaux et al., 2002). Le domaine MUN purifié peut faciliter l'ouverture de la syntaxine1 « fermée » pour l'assemblage ultérieur du complexe SNARE, indiquant un mécanisme pour les phénotypes observés chez les souris mutantes (Ma et al., 2011). Une observation frappante est que la fonction de Munc13 soit étroitement régulée par des voies de signalisation multiples. Entre autres, les isoformes neuronales de Munc13 lient le diacylglycérol et sont activées par les esters de phorbol (Betz et al., 1998). La liaison au domaine $\mathrm{C} 1 \mathrm{du}$ diacylglycérol régule la fonction synaptique, puisque des mutants de souris privés de la liaison du phorbol ester à Munc13 présentent une altération dramatique de l'activation et de la plasticité à court terme (Rhee et al., 2002). Le domaine $\mathrm{C} 2$ de liaison au $\mathrm{Ca}^{2+}$ de Munc13 est également important, puisqu'il contribue significativement à la plasticité des synapses (Shin et al., 2010). Finalement, Munc13s se lie à la calmoduline qui module sa fonction (Lipstein et al., 2013).

La délétion des RIM provoque également une altération importante de l'activation (Koushika et al., 2001; Schoh et al., 2002). Le mécanisme de cette altération semble cependant être indirect, parce que les RIM se lient à Munc13s et activent la fonction de Munc13 (Deng et al., 2011). Plus précisément, la séquence N-terminale des RIM comporte un motif à doigt de zinc qui se lie avec une forte affinité au domaine $\mathrm{C} 2 \mathrm{~N}$-terminal $\mathrm{Ca}^{2+}$ indépendant de Munc13 (Dulubova et al., 2005; Lu et al., 2006). En l'absence de cette liaison, le domaine C2 de Munc13-1 forme un homodimère constitutif ; lors de la liaison au doigt de zinc des RIM, l'homodimère se convertit en un hétérodimère RIM-Munc13. De manière frappante, nous avons trouvé que le défaut d'activation dans les synapses déficientes en RIM peut être compensé au moins partiellement par la surexpression d'un mutant de Munc13-1 tronqué à l'extrémité N-terminale, qui est privé du domaine $\mathrm{C} 2 \mathrm{~N}$-terminal et ne s'homodimérise plus, alors que la surexpression de Munc13-1 sauvage n'a aucun effet (Deng et al., 2011). Ces observations démontrent l'un des mécanismes par lequel les RIM régulent la fonction d'activation de Munc13, et sont compatibles avec un rôle central des RIM dans toutes les fonctions de la zone active.

\section{Le recrutement des canaux $\mathrm{Ca}^{2+}$ dans la zone active}

Pour permettre la libération rapide et synchrone d'un neurotransmetteur en réponse à un potentiel d'action, la condition la plus importante est que les canaux $\mathrm{Ca}^{2+}$ soient localisés dans la zone active adjacente aux vésicules synaptiques ancrées et activées. Un tel arrangement est le seul permettant des voies de diffusion du $\mathrm{Ca}^{2+}$ à courte distance nécessaires pour la rapidité de libération vésiculaire à la synapse, car le courant calcique pré-synaptique qui déclenche la libération est extrêmement bref - après tout, les senseurs calciques responsables de la libération de neurotransmetteur et de l'exocytose neuroendocrine sont les mêmes, bien qu'ils soient beaucoup plus lents dans le deuxième cas.

Un mécanisme moléculaire, expliquant comment les synapses réalisent l'arrangement requis des canaux $\mathrm{Ca}^{2+}$ et des vésicules synaptiques, a émergé avec la démonstration que les RIM collaborent avec leurs partenaires de liaison RIM-BP pour recruter des canaux calciques aux sites de libération (Kaeser et al., 2011 ; figure 13). Puisque les protéines RIM sont aussi les agents d'ancrage pour les vésicules synaptiques et qu'elles contribuent de manière cruciale à l'activation des vésicules, les RIM sont les éléments centraux dans l'organisation de la zone active et sont la base des propriétés étonnantes de la libération des neurotransmetteurs. Cette architecture simple de la zone active, dans laquelle une protéine unique est l'agent central de l'assemblage de tous les composants dans un site donné, est à la fois parcimonieuse et efficace (figure 14).

Nous avons montré que les RIM se lient directement et sélectivement aux canaux calciques dans 


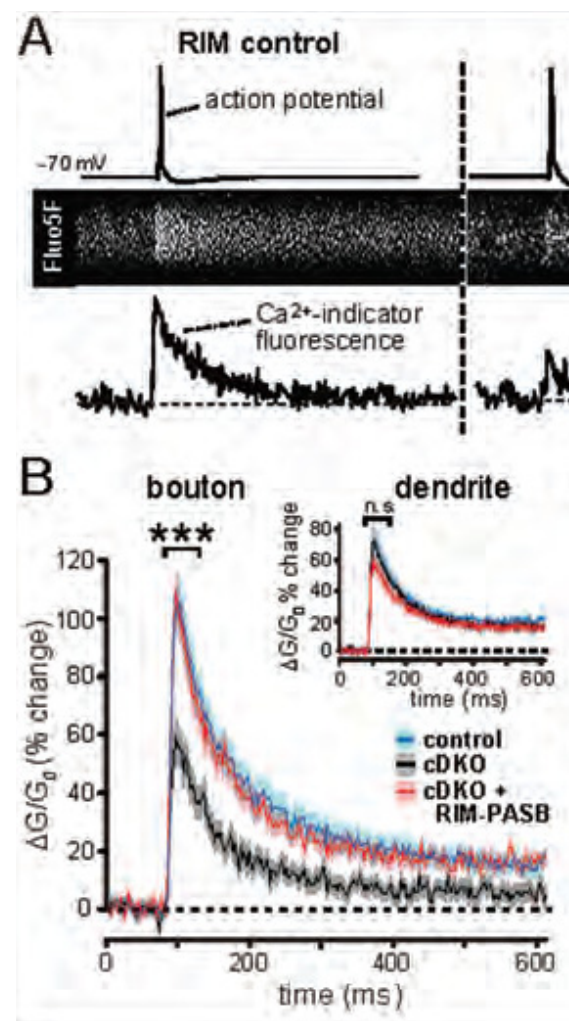

RIM cDKO
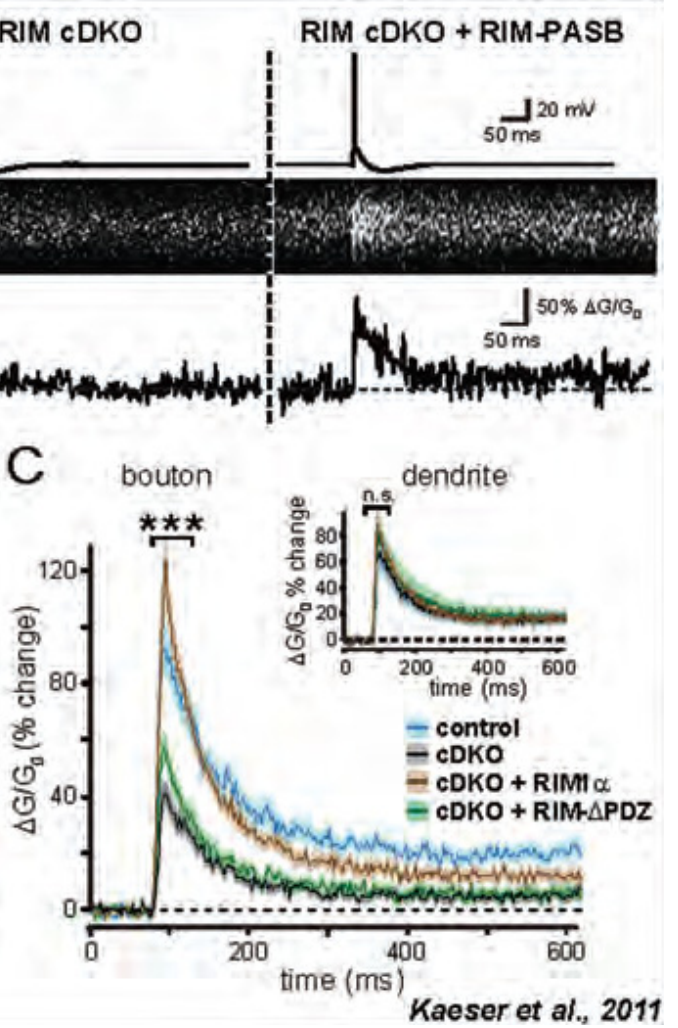

Fig. 13. La délétion des RIM diminue les potentiels calciques transitoires. A. Des potentiels d'action uniques provoquent une élévation des concentrations de $\mathrm{Ca}^{2+}$ pré-synaptiques; celle-ci est inhibée dans des neurones dépourvus de RIM (RIM cDKO), mais peut être restaurée par l'expression d'un fragment de RIM1 se liant aux canaux calciques (RIMPASB). En haut, tracés représentatifs de potentiels d'action; au milieu, scans linéaires de courants transitoires dans les boutons synaptiques, évoqués par ces potentiels d'action et suivis par la fluorescence de l'indicateur de $\mathrm{Ca}^{2+} \mathrm{Fluo5F}$; En bas, tracés des transitoires calciques. B. Relevés de l'évolution temporelle de la concentration intracellulaire de Ca ${ }^{2+}$ dans les terminaisons pré-synaptiques (bouton) et les dendrites pendant un potentiel d'action. Les tracés montrent la concentration moyenne de $\mathrm{Ca}^{2+}$ suivie comme en $\mathrm{A}$ au cours de multiples expériences indépendantes dans des neurones témoins, des neurones dépourvus de protéines RIM (cDKO), et des neurones RIMKO mais exprimant un fragment de RIM de liaison aux canaux calciques (cDKO+RIM-PASB). C. Identique à B, sinon que la restauration des courants calciques transitoires dans les synapses RIM déficientes a été testée pour RIM1 $\alpha$ sauvage de longueur normale ou pour RIM1 $\alpha$ sauvage dépourvue du domaine PDZ. Ces images sont issues de Kaeser et al. (2011).

les zones actives pré-synaptiques. De même que nous avons découvert le rôle des RIM dans l'ancrage/arrimage des vésicules, nous avons cherché à identifier leur rôle dans le recrutement des canaux $\mathrm{Ca}^{2+}$ dans la zone active, mais cette identification n'est devenue possible que lorsque avons délété toutes les isoformes de RIM des terminaisons pré-synaptiques (Kaeser et al., 2011). Nous avons trouvé que la délétion des RIM causait une chute de l'influx calcique pré-synaptique, une perte des canaux calciques pré-synaptiques et une perte du couplage étroit entre un potentiel d'action pré-synaptique et la libération (figure 1; Han et al., 2011; Kaeser et al., 2011, 2012). Les RIM remplissent leurs fonctions en formant un complexe avec les canaux calciques, avec d'autres protéines de zone active comme les RIM-BP (qui à leur tour se lient aussi aux canaux calciques), avec Munc13-1, et avec les vésicules synaptiques. Le rôle des RIM et des RIM-BP dans le recrutement des canaux calciques et l'ancrage des vésicules synaptiques aux zones actives est conservé dans l'évolution (Liu et al., 2011; Graf et al., 2012).

\section{Synthèse finale}

Les trois niveaux de libération que nous avons étudiés - fusion membranaire, déclenchement de la fusion par le $\mathrm{Ca}^{2+}$ et organisation de la machinerie de fusion - forment une hiérarchie de processus interdépendants. Comme des poupées russes, ces trois niveaux sont nichés les uns dans les autres, 


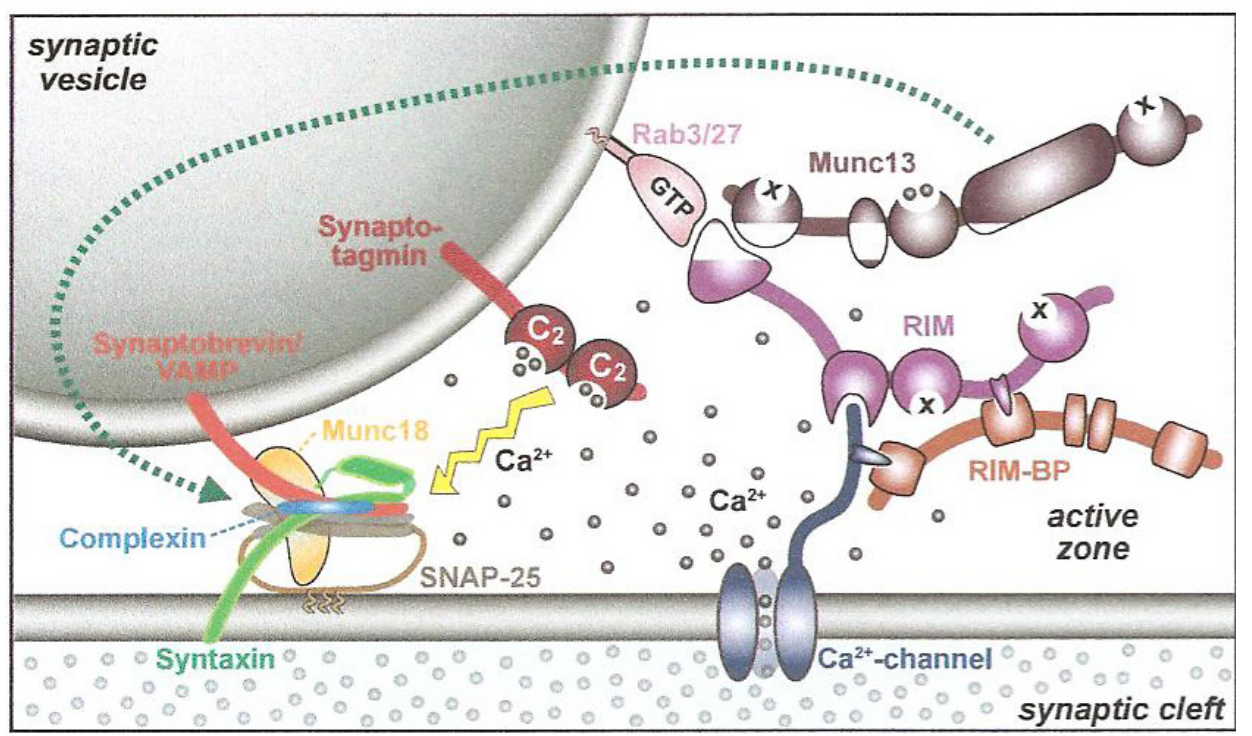

Fig. 14. Diagramme du complexe protéique RIM, RIM-BP, Munc13 qui se lie simultanément à Rab3/27 sur la vésicule synaptique et aux canaux calciques sur la membrane plasmique, réalisant ainsi l'ancrage des vésicules et des sites de libération, l'activation des vésicules en vue du largage (flèche pointillée) et le recrutement des canaux calciques adjacents aux vésicules ancrées. RIM, RIM-BP et Munc13 sont des protéines multidomaines qui forment un complexe dense remplissant trois fonctions essentielles des zones actives : recrutement des canaux calciques couplant étroitement les potentiels d'action au largage en localisant l'influx de $\mathrm{Ca}^{2+}$ à côté du senseur synaptotagmine; accrochage des vésicules au site de libération et activation dépendante de Munc13 de la machinerie de fusion composée de SNARE, syntaxine, SNAP25, synaptobrévine/VAMP et Munc18-1. Les ronds noirs schématisent les ions $\mathrm{Ca}^{2+}$; seuls les domaines $\mathrm{C} 2$ sont étiquetés. Les autres protéines de zone active se lient au complexe RIM/Munc13/RIM-BP, comme les $\alpha$-liprines et les ELK, et contribuent à la sécrétion mais ne sont pas montrées. Schéma adapté de Kaeser et al. (2011) et de Südhof (2012).

la fusion membranaire en est le cœur central et l'échafaudage qui organise les différents éléments en un mécanisme unique, en constitue la couche externe. Notre travail, avec celui d'autres chercheurs, a mis au jour un mécanisme plausible pour expliquer comment la membrane des vésicules synaptiques et la membrane plasmique opèrent une fusion rapide pendant la libération du neurotransmetteur, comment cette fusion est déclenchée par le $\mathrm{Ca}^{2+}$, et comment ces processus sont spatialement organisés dans la terminaison pré-synaptique, de telle sorte que l'ouverture des canaux calciques par un potentiel d'action permet la traduction rapide du signal calcique entrant en processus de fusion.

Dans son ensemble, la machinerie de libération du neurotransmetteur que nous avons découverte rend compte de la vitesse stupéfiante et de la précision de la décharge déclenchée par le $\mathrm{Ca}^{2+}$. De plus, le plan général de cette machinerie et l'identification des domaines régulateurs qui en font partie suggèrent des mécanismes qui expliquent l'impressionnante plasticité à court et long terme du largage, dont le rôle est crucial dans l'émergence des propriétés du circuit. Pourtant beaucoup de questions essentielles se posent encore. Par exemple, quels sont les mécanismes biochimiques qui sous-tendent la fusion membranaire, avec quelle précision les protéines SNARE et SM travaillent-elles, quel est le rôle de la machine de fusion décrite ici dans des désordres comme la maladie de Parkinson, comment les terminaisons présynaptiques subissent-elles les changements structuraux à long terme pendant la plasticité, et quel est le rôle de la plasticité dans la mémoire à long terme? Par ailleurs, quels mécanismes rendent-ils spécifiques les différents types de synapses - pourquoi les synapses inhibitrices par exemple présentent-elles souvent une probabilité de libération plus forte que celle des synapses excitatrices, et quels mécanismes confèrent des formes de plasticité distinctes à différents types de synapses? Comment la zone active pré-synaptique est-elle précisément alignée avec la densité postsynaptique et comment la taille d'une synapse est-elle régulée? Il y a encore beaucoup à faire et j'espère que certaines au moins de ces questions étonnantes seront abordées pendant le temps qui me reste à vivre.

Remerciements. Je remercie mes mentors scientifiques de toujours M.S. Brown, V.P. Whittaker et J.L. Goldstein pour leurs conseils permanents, et mes collègues et collaborateurs pour leur concours et leur soutien précieux, en particulier Reinhard Jahn, Robert E. Hammer, Nils Brose, 
Rafael Fernández-Chacón, Zhiping Pang, Irina Dubulova, Christian Rosenmund et Josep Rizo. Je suis reconnaissant à l'Institut Médical Howard Hughes, au NIMH et au NINDS pour leur soutien financier depuis presque trente ans.

\section{Références}

Acuna, C., Guo, Q., Burre, J., Sharma, M., Sun, J., and Südhof, T.C. (2014). Microsecond Dissection of Neurotransmitter Release: SNARE-Complex Assembly Dictates Speed and $\mathrm{Ca}^{2+}$-Sensitivity. Neuron, 82, 1088-1100.

Ahmad, M., Polepalli, J.S., Goswami, D., Yang, X., Kaeser-Woo, Y.J., Südhof, T.C., and Malenka, R.C. (2012). Postsynaptic Complexin Controls AMPA Receptor Exocytosis During LTP. Neuron, 73, 260-267.

Augustin, I., Rosenmund, C., Südhof, T.C., and Brose, N. (1999). Munc-13 is essential for fusion competence of glutamatergic synaptic vesicles. Nature, 400, 457-461.

Bacaj, T., Wu, D., Yang, X., Morishita, W., Zhou, P., Xu, W., Malenka, R.C., and Südhof, T.C. (2013). Synaptotagmin-1 and -7 Trigger Synchronous and Asynchronous Phases of Neurotransmitter Release. Neuron, 80, 947-959.

Balch, W.E., Dunphy, W.G., Braell, W.A., and Rothman, J.E. (1984). Reconstitution of the transport of protein between successive compartments of the Golgi measured by the coupled incorporation of N-acetylglucosamine. Cell, 39, 405-416.

Betz, A., Ashery, U., Rickmann, M., Augustin, I., Neher, E., Südhof, T.C., Rettig, J., and Brose, N. (1998). Munc13-1 is a presynaptic phorbol ester receptor that enhances neurotransmitter release. Neuron, 21, 123-36.

Betz, A., Thakur, P., Junge, H.J., Ashery, U., Rhee, J.S., Scheuss, V., Rosenmund, C., Rettig, J. and Brose, N. (2001). Functional interaction of the active zone proteins Munc13-1 and RIM1 in synaptic vesicle priming. Neuron, 30, 183-196.

Blasi, J., Chapman, E.R., Yamasaki, S., Binz, T., Niemann, H., and Jahn, R. (1993a). Botulinum neurotoxin $\mathrm{C} 1$ blocks neurotransmitter release by means of cleaving HPC-1/syntaxin. EMBO J, 12, 4821-4828.

Blasi, J., Chapman, E.R., Link, E., Binz, T., Yamasaki, S., De Camilli, P., Südhof, T.C., Niemann, H., and Jahn, R. (1993b). Botulinum neurotoxin A selectively cleaves the synaptic protein SNAP-25. Nature, 365, 160-163.

Bollmann, J.H., Sakmann, B., and Borst, J.G. (2000). Calcium sensitivity of glutamate release in a calyx-type terminal. Science, 289, 953-957.

Borst, J.G., and Sakmann, B. (1996). Calcium influx and transmitter release in a fast CNS synapse. Nature, 383 , 431-434.

Brenner, S. (1974). The genetics of Canorhabditis elegans. Genetics, 77, 71-94.

Brose, N., Petrenko, A.G., Südhof, T.C., and Jahn, R. (1992). Synaptotagmin: $\mathrm{A} \mathrm{Ca}^{2+}$-sensor on the synaptic vesicle surface. Science, 256, 1021-1025.
Burré, J., Sharma, M., Tsetsenis, T., Buchman, V., Etherton, M.R., and Südhof, T.C. (2010). $\alpha$-Synuclein Promotes SNARE-Complex Assembly in Vivo and in Vitro. Science, 329, 1663-1667.

Cao, P., Maximov, A., and Südhof, T.C. (2011). ActivityDependent IGF-1 Exocytosis is Controlled by the $\mathrm{Ca}^{2+}$-Sensor Synaptotagmin-10. Cell, 145, 300-311.

Cao, P., Yang, X., and Südhof, T.C. (2013). Complexin Activates Exocytosis of Distinct Secretory Vesicles Controlled by Different Synaptotagmins. J Neurosci, 33, 1714-1727.

Carr, C.M., Grote, E., Munson, M., Hughson, F.M., and Novick, P.J. (1999). Sec1p binds to SNARE complexes and concentrates at sites of secretion. J Cell Biol, 146, 333-344.

Ceccarelli, B., Hurlbut, W.P., and Mauro A. (1973). Turnover of transmitter and synaptic vesicles at the frog neuromuscular junction. J Cell Biol, 57, 499-524.

Chandra, S., Gallardo, G., Fernández-Chacón, R., Schlüter, O.M., and Südhof, T.C., (2005). $\alpha$ Synuclein Cooperates with $\mathrm{CSP} \alpha$ in Preventing Neurodegeneration. Cell, 123, 383-396.

Chapman, E.R., Hanson, P.I., An, S., and Jahn, R. (1995). $\mathrm{Ca}^{2+}$ regulates the interaction between synaptotagmin and syntaxin 1. J Biol Chem, 270, 23667-23671.

Chen, X., Tomchick, D.R., Kovrigin, E., Araç, D., Machius, M., Südhof, T.C., and Rizo, J. (2002). Threedimensional structure of the complexin/SNARE complex. Neuron, 33, 397-409.

Clary, D.O., Griff, I.C., and Rothman, J.E., (1990). SNAPs, a family of NSF attachment proteins involved in intracellular membrane fusion in animals and yeast. Cell, 61, 709-721.

Coussens, L., Parker, P.J., Rhee, L., Yang-Feng, T.L., Chen, E., Waterfield, M.D., Francke, U., and Ullrich, A. (1986). Multiple, distinct forms of bovine and human protein kinase $\mathrm{C}$ suggest diversity in cellular signaling pathways. Science, 233, 859-866.

Corbalan-Garcia, S., and Gómez-Fernández, J.C. (2014). Signaling through C2 domains: More than one lipid target. Biochim Biophys Acta, 1838, 1536-1547.

Davletov, B.A., and Südhof, T.C. (1993). A single C2domain from synaptotagmin $\mathrm{I}$ is sufficient for high affinity $\mathrm{Ca}^{2+}$ /phospholipid-binding. J Biol Chem, 268, 26386-26390.

Davletov, B.A., and Südhof, T.C. (1994). $\mathrm{Ca}^{2+}$-dependent conformational change in synaptotagmin I. J Biol Chem, 269, 28547-28550.

Deák, F., Shin, O.H., Tang, J., Hanson, P., Ubach, J., Jahn, R., Rizo, J., Kavalali, E.T., and Südhof, T.C. (2006). Rabphilin Regulates SNARE-Dependent RePriming of Synaptic Vesicles for Fusion. EMBO J, 25, 2856-2866.

de Wit, H., Walter, A.M., Milosevic, I., Gulyás-Kovács, A., Riedel, D., Sørensen, J.B., and Verhage, M. (2009). Synaptotagmin-1 docks secretory vesicles to Syntaxin1/SNAP-25 acceptor complexes. Cell, 138, 935-946. 
Deng, L., Kaeser, P.S., Xu, W., and Südhof, T.C. (2011). RIM Proteins Activate Vesicle Priming by Reversing Auto-Inhibitory Homodimerization of Munc13. Neuron, 69, 317-331.

DiAntonio, A., Parfitt, K.D., and Schwarz, T.L. (1993). Synaptic transmission persists in synaptotagmin mutants of Drosophila. Cell, 73, 1281-1290.

Dulubova, I., Sugita, S., Hill, S., Hosaka, M., Fernandez, I., Südhof, T.C., and Rizo, J. (1999). A conformational switch in syntaxin during exocytosis. EMBO J, 18, 4372-4382.

Dulubova, I., Yamaguchi, T., Gao, Y., Min, S.W., Huryeva, I., Südhof, T.C., and Rizo, J. (2002). How Tlg2p/syntaxin16 'snares' Vps45. EMBO J, 21, 3620-3631.

Dulubova, I., Lou, X., Lu, J., Huryeva, I., Alam, A., Schneggenburger, R., Südhof, T.C., and Rizo, J. (2005). A Munc13/RIM/Rab3 Tripartite Complex: From Priming to Plasticity? EMBO J, 24, 2839-2850.

Dulubova, I., Khvotchev, M., Südhof, T.C., and Rizo, J. (2007). Munc18-1 Binds Directly to the Neuronal SNARE Complex. Proc Natl Acad Sci USA, 104, 2697-2702.

Fenster, S.D., Chung, W.J., Zhai, R., Cases-Langhoff, C., Voss, B., Garner, A.M., Kaempf, U., Kindler, S., Gundelfinger, E.D., and Garner, C.C. (2000). Piccolo, a presynaptic zinc finger protein structurally related to bassoon. Neuron, 25, 203-214.

Fernandez, I., Ubach, J., Dulubova, I., Zhang, X., Südhof, T.C., and Rizo, J. (1998). Three-dimensional structure of an evolutionarily conserved N-terminal domain of syntaxin 1A. Cell, 94, 841-849.

Fernandez, I., Araç, D., Ubach, J., Gerber, S.H., Shin, O., Gao, Y., Anderson, R.G., Südhof, T.C. and Rizo, J. (2001). Three-dimensional structure of the synaptotagmin 1 C2B-domain: Synaptotagmin 1 as a phospholipid binding machine. Neuron, 32, 1057-1069.

Fernández-Chacón, R., and Südhof, T.C. (2000). Novel SCAMPs lacking NPF repeats: ubiquitous and synaptic vesicle-specific forms implicate SCAMPs in multiple membrane-trafficking functions. J Neurosci, 20, 7941-7950.

Fernández-Chacón, R., Königstorfer, A., Gerber, S.H., García, J., Matos, M.F., Stevens, C.F., Brose, N., Rizo, J., Rosenmund, C., and Südhof, T.C. (2001). Synaptotagmin I functions as a $\mathrm{Ca}^{2+}$-regulator of release probability. Nature, 410, 41-49.

Fernández-Chacón, R., Wölfel, M., Nishimune, H., Tabares, L., Schmitz, F., Castellano-Muñoz, M., Rosenmund, C., Montesinos, M.L., Sanes, J.R., Schneggenburger, R., and Südhof, T.C. (2004). The synaptic vesicle protein $\operatorname{CSP} \alpha$ prevents presynaptic degeneration. Neuron, 42, 237-251.

Forsythe, I.D. (1994). Direct patch recording from identified presynaptic terminals mediatingglutamatergic EPSCs in the rat CNS, in vitro. J Physiol, 479, 381-387.

Garcia, E.P., Gatti, E., Butler, M., Burton, J., and De Camilli, P. (1994). A rat brain Sec1 homologue related to Rop and UNC18 interacts with syntaxin. Proc Natl Acad Sci USA, 91, 2003-2007.
Geppert, M., Archer, B.T. III, and Südhof, T.C. (1991). Synaptotagmin II: a novel differentially distributed form of synaptotagmin. J Biol Chem, 266, 1354813552.

Geppert, M., Goda, Y., Hammer, R.E., Li, C., Rosahl, T.W., Stevens, C.F., and Südhof, T.C. (1994a). Synaptotagmin I: A major $\mathrm{Ca}^{2+}$-sensor for transmitter releaseat a central synapse. Cell, 79, 717-727.

Geppert, M., Bolshakov, V.Y., Siegelbaum, S.A., Takei, K., De Camilli, P., Hammer, R.E., and Südhof, T.C. (1994b). The role of Rab3A in neurotransmitter release. Nature, 369, 493-497.

Gerber, S.H., Rah, J.C., Min, S.W., Liu X, de Wit, H., Dulubova, I., Meyer, A.C., Rizo, J., Arancillo, M., Hammer, R.E., Verhage, M., Rosenmund, C., and Südhof, T.C. (2008). Conformational Switch of Syntaxin-1 Controls Synaptic Vesicle Fusion. Science, 321, 1507-1510.

Giraudo, C.G., Eng, W.S., Melia, T.J., and Rothman, J.E. (2006). A clamping mechanism involved in SNAREdependent exocytosis. Science, 313, 676-680.

Gracheva, E.O., Hadwiger, G., Nonet, M.L., and Richmond, J.E. (2008). Direct interactions between $C$. elegans RAB-3 and Rim provide a mechanism to target vesicles to the presynaptic density. Neurosci Lett, 444, 137-142.

Graf, E.R., Valakh V, Wright, C.M., Wu, C, Liu, Z., Zhang, Y.Q., and DiAntonio, A. (2012). RIM promotes calcium channel accumulation at active zones of the Drosophila neuromuscular junction. J Neurosci, 32, 16586-16596.

Grote, E., Carr, C.M., and Novick, P.J. (2000). Ordering the final events in yeast exocytosis. J Cell Biol, 151, 439-452.

Grumelli, C., Verderio, C., Pozzi, D., Rossetto, O., Montecucco, C., and Matteoli, M., (2005). Internalization and mechanism of action of clostridial toxins in neurons. Neurotoxicology, 26, 761-767.

Gundersen, C.B., Mastrogiacomo, A, Faull, K., and Umbach, J.A. (1994). Extensive lipidation of a Torpedo cysteine string protein. J Biol Chem, 269, 19197-19199.

Gustavsson, N., Lao, Y., Maximov, A., Chuang, J.C., Kostromina E., Repa, J.J., Li, C, Radda, G.K., Südhof, T.C., and Han, W. (2008). Impaired insulin secretion and glucose intolerance in Synaptotagmin-7 null mutant mice. Proc Natl Acad Sci USA, 105, 3992-3997.

Gustavsson, N., Wei, S.H., Hoang, D.N., Lao, Y., Zhang, Q., Radda, G.K., Rorsman, P., Südhof, T.C., and Han, W. (2009). Synaptotagmin-7 is a principal $\mathrm{Ca}^{2+}$ sensor for $\mathrm{Ca}^{2+}$-induced glucagon exocytosis in pancreas. $J$ Physiol, 587, 1169-1178.

Han, Y., Kaeser, P.S., Südhof, T.C., and Schneggenburger, R. (2011). RIM determines $\mathrm{Ca}^{2+}$-channel density and vesicle docking at the presynaptic active zone. Neuron, 69, 304-316.

Hanson, P.I., Roth, R, Morisaki, H, Jahn, R., and Heuser, J.E. (1997). Structure and conformational changes in $\mathrm{NSF}$ and its membrane receptor complexes visualized by quick-freeze/deep-etch electron microscopy. Cell, 90, 523-535. 
Harrison, S.D., Broadie, K., van de Goor, J., and Rubin, G.M. (1994). Mutations in the Drosophila Rop gene suggest a function in general secretion and synaptic transmission. Neuron, 13, 555-566.

Hata, Y., Slaughter, C.A., and Südhof, T.C. (1993). Synaptic vesicle fusion complex contains unc-18 homologue bound to syntaxin. Nature, 366, 347-351.

Hata, Y., Butz, S., Sudhof, T.C. (1996) CASK: A novel dlg/PSD95 homolog with an N-terminal calmodulindependent protein kinase domain identified by interaction with neurexins. J Neurosci, 16, 2488-2494.

Hayashi, T., McMahon, H., Yamasaki, S., Binz, T., Hata, Y., Südhof, T.C., and Niemann, H. (1994). Synaptic vesicle membrane fusion complex: Action of clostridial neurotoxins on assembly. EMBO J, 13, 5051-5061.

Heuser, J.E., and Reese, T.S. (1973). Evidence for recycling of synaptic vesicle membrane during transmitter release at the frog neuromuscular junction. J Cell Biol, $57,315-344$.

Huntwork, S., and Littleton, J.T. (2007). A complexin fusion clamp regulates spontaneous neurotransmitter release and synaptic growth. Nat Neurosci, 10, 1235-1237.

Ishizuka, T., Saisu, H., Odani, S., and Abe, T. (1995). Synaphin: a protein associated with the docking/fusion complex in presynaptic terminals. Biochem Biophys Res Commun, 213, 1107-1114.

Janz, R., Hofmann, K. and Südhof, T.C. (1998). SVOP, an evolutionarily conserved synaptic vesicle protein, suggests novel transport functions of synaptic vesicles. J Neurosci, 18, 9269-9281.

Janz, R., Südhof, T.C., Hammer, R.E., Unni, V., Siegelbaum, S.A., and Bolshakov, V.Y. (1999). Essential roles in synaptic plasticity for synaptogyrin I and synaptophysin I. Neuron, 24, 687-700.

Katz, B. (1969). The Release of Neural Transmitter Substances. Liverpool, Liverpool Univ. Press.

Kaeser, P.S., Deng, L., Wang, Y., Dulubova, I., Liu, X., Rizo, J., and Südhof, T.C. (2011). RIM proteins tether $\mathrm{Ca}^{2+}$-channels to presynaptic active zones via a direct PDZ-domain interaction. Cell, 144, 282-295.

Kaeser, P.S., Deng, L, Fan, M., and Südhof, T.C. (2012). RIM Genes Differentially Contribute to Organizing Presynaptic Release Sites. Proc Natl Acad Sci USA, 109, 11830-11835.

Kaeser-Woo, Y.J., Yang, X., and Südhof, T.C. (2012). Cterminal Complexin Sequence is Selectively Required for Clamping and Priming but Not for $\mathrm{Ca}^{2+}$-Triggering of Synaptic Exocytosis. J Neurosci, 32, 2877-2885.

Khvotchev, M., Dulubova, I., Sun, J., Dai, H., Rizo, J., and Südhof, T.C. (2007). Dual Modes of Munc181/SNARE Interactions Are Coupled by Functionally Critical Binding to Syntaxin-1 N-terminus. J Neurosci, 27, 12147-12155.

Koushika, S.P., Richmond, J.E., Hadwiger, G., Weimer, R.M., Jorgensen, EM. and Nonet, M.L. (2001). A postdocking role for active zone protein Rim. Nat Neurosci, 4, 997-1005.

Lee, J.O., Yang, H., Georgescu, M.M., Di Cristofano, A., Maehama, T., Shi, Y., Dixon, J.E., Pandolfi, P., and
Pavletich, N.P. (1999). Crystal structure of the PTEN tumor suppressor: implications for its phosphoinositide phosphatase activity and membrane association. Cell, 99, 323-334.

Li, C, Ullrich, B, Zhang, J.Z., Anderson, R.G., Brose, N., and Südhof, T.C. (1995a) $\mathrm{Ca}^{2+}$-dependent and $\mathrm{Ca}^{2+}$-independent activities of neural and non neuronal synaptotagmins. Nature, 375, 594-599.

Li, C., Davletov, B.A., and Südhof, T.C. (1995b). Distinct $\mathrm{Ca}^{2+}$ - and $\mathrm{Sr}^{2+}$-binding properties of synaptotagmins: definition of candidate $\mathrm{Ca}^{2+}$-sensors for the fast and slow components of neurotransmitter release. $J$ Biol Chem, 270, 24898-24902.

Lin, R.C., and Scheller, R.H. (1997). Structural organization of the synaptic exocytosis core complex. Neuron, 19, 1087-1094.

Link, E., Edelmann, L., Chou, J.H., Binz, T., Yamasaki, S., Eisel, U., Baumert, M., Südhof, T.C., Niemann, H., and Jahn, R. (1992). Tetanus toxin action: Inhibition of neurotransmitter release linked to synaptobrevin poteolysis. Biochem Biophys Res Comm, 189, 1017-1023.

Lipstein, N., Sakaba, T., Cooper, B.H., Lin, K.H., Strenzke, N., Ashery, U., Rhee, J.S., Taschenberger, H., Neher, E., and Brose, N. (2013). Dynamic control of synaptic vesicle replenishment and short term plasticity by $\mathrm{Ca}^{2+}$-calmodulin-Munc13-1 signaling. Neuron, $79,82-96$.

Littleton, J.T., Stern, M., Schulze, K., Perin, M., and Bellen, H.J. (1993). Mutational analysis of Drosophila synaptotagmin demonstrates its essential role in $\mathrm{Ca}^{2+}$. activated neurotransmitter release. Cell, 74, 1125-1134.

Liu, K.S., Siebert, M., Mertel, S., Knoche, E., Wegener, S., Wichmann, C., Matkovic, T., Muhammad, K., Depner, H., Mettke, C., Bückers, J., Hell, S.W., Müller, M., Davis, G.W., Schmitz, D., and Sigrist, S.J. (2011). RIM-binding protein, a central part of the active zone, is essential for neurotransmitter release. Science, 334, $1565-1569$.

Lu, J., Machius, M., Dulubova, I., Dai, H., Südhof, T.C., Tomchick, D.R., and Rizo, J. (2006). Structural Basis for a Munc13-1 Homodimer-Munc13-1/RIM Heterodimer Switch: C2-domains as Versatile ProteinProtein Interaction Modules. PLOS Biology, 4, e192.

Ma, C., Li, W., Xu, Y., and Rizo, J. (2011). Munc13 mediates the transition from the closed syntaxin-Munc18 complex to the SNARE complex. Nat Struct Mol Biol, $18,542-549$.

Mackler, J.M., and Reist, N.E. (2001). Mutations in the second $\mathrm{C} 2$ domain of synaptotagmine disrupt synaptic transmission at Drosophila neuromuscular junctions. J Comp Neurol, 436, 4-16.

Maroteaux, L., Campanelli, J.T., and Scheller, R.H. (1988). Synuclein: a neuron-specific protein localized to the nucleus and presynaptic nerve terminal. J Neurosci, 8, 2804-2815.

Matthew, W.D., Tsavaler, L and Reichardt, L.F. (1981). Identification of a synaptic vesicle specific membrane protein with a wide distribution in neuronal and neurosecretory tissue. J Cell Biol, 91, 257-269. 
Maximov, A., and Südhof, T.C. (2005). Autonomous Function of Synaptotagmin 1 in Triggering Synchronous Release Independent of Asynchronous Release. Neuron, 48, 547-554.

Maximov, A., Lao, Y., Li, H., Chen, X., Rizo, J., Sørensen, J.B., and Südhof, T.C. (2008). Genetic analysis of Synaptotagmin-7 function in synaptic vesicle exocytosis. Proc Natl Acad Sci USA, 105, 3986-3991.

Maximov, A., Tang, J., Yang, X., Pang, Z.P., and Südhof, T.C. (2009). Complexin Controls the Force Transfer from SNARE complexes to membranes in Fusion. Science, 323, 516-521.

Mayer, A., Wickner, W., and Haas, A. (1996). Sec18p (NSF)-driven release of Sec17p (alpha-SNAP) can precede docking and fusion of yeast vacuoles. Cell, 85, 83-94.

McMahon, H., Ushkaryov, Y.A., Edelmann, L., Link, E., Binz, T., Niemann, H., Jahn, R., and Südhof, T.C. (1993). Cellubrevin: A ubiquitous tetanus-toxin substrate homologous to a putative synaptic vesicle fusion protein. Nature, 364, 346-349.

McMahon, H.T., and Südhof, T.C. (1995). Synaptic core complex of synaptobrevin, syntaxin, and SNAPS forms high affinity $\alpha$-SNAP binding site. J Biol Chem, 270, 2213-2217.

McMahon, H.T., Missler, M., Li, C. and Südhof, T.C. (1995). Complexins: cytosolic proteins that regulate SNAP-receptor function. Cell, 83, 111-119.

Meijer, M., Burkhardt, P., de Wit, H., Toonen, R.F., Fasshauer, D., and Verhage, M. (2012). Munc18-1 mutations that strongly impair SNARE-complex binding support normal synaptic transmission. EMBO J, 31, 2156-2168.

Neher, E., and Penner, R. (1994) Mice sans synaptotagmin [news]. Nature, 372, 316-317.

Nonet, M.L., Grundahl, K., Meyer, B.J., and Rand, J.B. (1993). Synaptic function is impaired but not eliminated in $C$. elegans mutants lacking synaptotagmin. Cell, 73, 1291-1305.

Novick, P., and Schekman, R. (1979). Secretion and cellsurface growth are blocked in a temperature-sensitive mutant of Saccharomyces cerevisiae. Proc Natl Acad Sci USA, 76, 1858-1862.

Ohtsuka, T., Takao-Rikitsu, E., Inoue, E., Inoue, M., Takeuchi, M., Matsubara, K., Deguchi-Tawarada, M., Satoh, K., Morimoto, K., Nakanishi, H., and Takai, Y. (2002). Cast: a novel protein of the cytomatrix at the active zone of synapses that forms a ternary complex with RIM1 and munc13-1. J Cell Biol, 158, 577-590.

Pang, Z.P., Shin, O.H., Meyer, A.C., Rosenmund, C., and Südhof, T.C. (2006a). A gain-of-function mutation in Synaptotagmin-1 reveals a critical role of $\mathrm{Ca}^{2+}$ dependent SNARE-complex binding in synaptic exocytosis. J Neurosci, 26, 12556-12565.

Pang, Z.P., Sun, J., Rizo, J., Maximov, A., and Südhof, T.C. (2006b). Genetic Analysis of Synaptotagmin 2 in Spontaneous and $\mathrm{Ca}^{2+}$-Triggered Neurotransmitter Release. EMBO J, 25, 2039-2050.
Pang, Z.P., Melicoff, E., Padgett, D., Liu, Y., Teich, A.F., Dickey, B.F., Lin, W., Adachi, R., and Südhof, T.C. (2007). Synaptotagmin-2 is Essential for Survival and Contributes to $\mathrm{Ca}^{2+}$-Triggering of Neurotransmitter Release in Central and Neuromuscular Synapses. J Neurosci, 26, 13493-13504.

Perin, M.S., Fried, V.A., Slaughter, C.A., and Südhof, T.C. (1988). The structure of cytochrome b561, a secretory vesicle-specific electron transport protein. EMBO J, 7, 2697-2703.

Perin, M.S., Fried, V.A., Mignery, G.A., Jahn, R., Südhof, T.C. (1990). Phospholipid binding by a synaptic vesicle protein homologous to the regulatory region of protein kinase C. Nature, 345, 260-263.

Perin, M.S., Fried, V.A., Stone, D.K., Xie, X.S., and Südhof, T.C. (1991a). Structure of the $116 \mathrm{kDa}$ polypeptide of the clathrin-coated vesicle/synaptic vesicle proton pump. J Biol Chem, 266, 3877-3881.

Perin, M.S., Johnston, P.A., Ozcelik, T., Jahn, R., Francke, U., and Südhof, T.C. (1991b). Structural and functional conservation of synaptotagmin (p65) in Drosophila and humans. J Biol Chem, 266, 615-622.

Pevsner, J., Hsu, S.C., and Scheller, R.H. (1994). n-Sec1: a neural-specific syntaxin-binding protein. Proc Natl Acad Sci USA, 91, 1445-1449.

Poirier, M.A., Xiao, W., Macosko, J.C., Chan, C., Shin, Y.K., and Bennett, M.K. (1998). The synaptic SNARE complex is a parallel four-stranded helical bundle. Nat Struct Biol, 5, 765-769.

Rathore, S.S., Bend, E.G., Yu, H., Hammarlund, M., Jorgensen, E.M., and Shen, J. (2010). Syntaxin Nterminal peptide motif is an initiation factor for the assembly of the SNARE-Sec1/Munc18 membrane fusion complex. Proc Natl Acad Sci USA, 107, 22399-22406.

Regehr, W.G. (2012). Short-term presynaptic plasticity. Cold Spring Harb Perspect Biol, 4, a005702.

Reim, K., Mansour, M., Varoqueaux, F., McMahon, H.T., Südhof, T.C., Brose, N., and Rosenmund, C. (2001). Complexins regulate the $\mathrm{Ca}^{2+}$-sensitivity of the synaptic neurotransmitter release machinery. Cell, 104, 71-81.

Rhee, J.S., Betz, A., Pyott, S., Reim, K., Varoqueaux, F., Augustin, I., Hesse, D., Südhof, T.C., Takahashi, M., Rosenmund, C., and Brose, N. (2002). Beta phorbol ester- and diacylglycerol-induced augmentation of transmitter release is mediated by Munc13s and not by PKCs. Cell, 108, 121-133.

Rizo, J. and Südhof, T.C. (1998). C2-domains, structure of a universal $\mathrm{Ca}^{2+}$-binding domain". J Biol Chem, 273, 15879-15882.

Rizo, J., and Südhof, T.C. (2012). The Membrane Fusion Enigma: SNAREs, SM Sec1/Munc18 Proteins, and Their Accomplices - Guilty as Charged? Annu Rev Cell Dev Biol, 28, 279-308.

Robinson, I.M., Ranjan, R., and Schwarz, T.L. (2002). Synaptotagmin I and IV promote transmitter release independently of $\mathrm{Ca}^{2+}$ binding in the $\mathrm{C} 2 \mathrm{~A}$ domain. Nature, 418, 336-340. 
Rosahl, T.W., Geppert, M., Spillane, D., Herz, J., Hammer, R.E., Malenka, R.C., and Südhof, T.C. (1993). Short term synaptic plasticity is altered in mice lacking synapsin I. Cell, 75, 661-670.

Sabatini, B.L., and Regehr, W.G. (1996). Timing of neurotransmission at fast synapses in the mammalian brain. Nature, 384, 170-172.

Salminen, A., and Novick, P.J. (1987). A ras-like protein is required for a post-Golgi event in yeast secretion. Cell, $49,527-538$.

Schiavo, G., Benfenati, F., Poulain, B., Rossetto, O., Polverino de Laureto, P., DasGupta, B.R., and Montecucco, C. (1992). Tetanus and botulinum-B neurotoxins block neurotransmitter release by proteolytic cleavage of synaptobrevin. Nature, 359, 832-835.

Schiavo, G., Rossetto, O., Catsicas, S., Polverino de Laureto, P., DasGupta, B.R., Benfenati, F., and Montecucco, C. (1993). Identification of the nerve terminal targets of botulinum neurotoxin serotypes A, D, and E. J Biol Chem, 268, 23784-23787.

Schlüter, O.M., Schnell, E., Verhage, M., Tzonopoulos, T., Nicoll, R.A., Janz, R., Malenka, R.C., Geppert, M., and Südhof, T.C. (1999). Rabphilin knock-out mice reveal rat rabphilin is not required for rab3 function in regulating neurotransmitter release. J Neurosci, 19, 5834-5846.

Schlüter, O.M., Schmitz, F., Jahn, R., Rosenmund, C., and Südhof, T.C. (2004). A complete genetic analysis of neuronal Rab3 function. J Neurosci, 24, 6629-6637.

Schlüter, O.M., Südhof, T.C., and Rosenmund, C. (2006). Rab3 Superprimes Synaptic Vesicles for Release: Implications for Short Term Synaptic Plasticity. J Neurosci, 26, 1239-1246.

Schneggenburger, R., and Neher, E. (2000). Intracellular calcium dependence of transmitter release rates at a fast central synapse. Nature, 406, 889-893.

Schoch, S., Castillo, P.E., Jo, T., Mukherjee, K., Geppert, M., Wang, Y., Schmitz, F., Malenka, R.C., and Südhof, T.C. (2002). RIM1 $\alpha$ forms a protein scaffold for regulating neurotransmitter release at the active zone. Nature, 415, 321-326.

Schonn, J., Maximov, A., Lao, Y., Südhof, T.C., and Sørensen, J.B. (2008). Synaptotagmin-1 and -7 are functionally overlapping $\mathrm{Ca}^{2+}$ sensors for exocytosis in adrenal chromaffin cells. Proc Natl Acad Sci USA, 105, 3998-4003.

Shao, X., Davletov, B.A., Sutton, R.B., Südhof, T.C., and Rizo, J. (1996). Bipartite $\mathrm{Ca}^{2+}$-binding motif in C2 domains of synaptotagmin and protein kinase C. Science, $273,248-251$

Shao, X., Li, C., Fernandez, I., Zhang, X., Südhof, T.C., and Rizo, J. (1997). Synaptotagmin-syntaxin interaction: the $\mathrm{C} 2$-domain as a $\mathrm{Ca}^{2+}$-dependent electrostatic switch. Neuron, 18, 133-142.

Shao, X., Fernandez, I., Südhof, T.C., and Rizo, J. (1998). Solution structures of the $\mathrm{Ca}^{2+}$-free and $\mathrm{Ca}^{2+}$ bound $\mathrm{C} 2 \mathrm{~A}$ domain of synaptotagmin I: does $\mathrm{Ca}^{2+}$ induce a conformational change? Biochemistry, 37, 16106-16115.
Sharma, M., Burré, J., Bronk, P., Zhang, Y., Xu, W., and Südhof, T.C. (2011a). CSP $\alpha$ Knockout Causes Neurodegeneration by Impairing SNAP-25 Function. EMBO J, 31, 829-841.

Sharma, M., Burré, J., and Südhof, T.C. (2011b). CSP $\alpha$ Promotes SNARE-Complex Assembly by Chaperoning SNAP-25 during Synaptic Activity. Nature Cell Biol, $13,30-39$.

Sharma, M., Burré, J., and Südhof, T.C. (2012). Proteasome Inhibition Alleviates SNARE-Dependent Neurodegeneration in $\operatorname{CSP} \alpha$ Knockout Mice. Science Transl Medicine, 4, 147ra113.

Shen, J., Tareste, D.C., Paumet, F., Rothman, J.E., and Melia, T.J. (2007). Selective activation of cognate SNAREpins by Sec1/Munc18 proteins. Cell, 128, 183-195.

Shirataki, H., Kaibuchi, K., Sakoda, T., Kishida, S., Yamaguchi, T., Wada, K., Miyazaki, M., and Takai, Y. (1993). Rabphilin-3A, a putative target protein for smg p25A/rab3A p25 small GTP-binding protein related to synaptotagmin. Mol Cell Biol, 13, 2061-2068.

Shin, O.H., Rhee, J.S., Tang, J., Sugita, S., Rosenmund, C., and Südhof, T.C. (2003). $\mathrm{Sr}^{2+}$-Binding to the $\mathrm{Ca}^{2+}$-Binding Site of the Synaptotagmin 1 C2BDomain Triggers Fast Exocytosis Without Stimulating SNARE Interactions. Neuron, 37, 99-108.

Shin, O.H., Xu, J., Rizo, J., and Südhof, T.C. (2009). Differential but convergent functions of $\mathrm{Ca}^{2+}$-binding to Synaptotagmin-1 C2-domains mediate neurotransmitter release. Proc Natl Acad Sci USA, 106, 16469-16474.

Shin, O.H., Lu, J., Rhee, J.S., Tomchick, D.R., Pang, Z.P., Wojcik, S.M., Camacho-Perez, M., Brose, N., Machius, M., Rizo, J., Rosenmund, C., and Südhof, T.C. (2010). Munc13 C2B-domain - an activity-dependent $\mathrm{Ca}^{2+}$ regulator of synaptic exocytosis. Nature Struct $\mathrm{Mol}$ Biol, 17, 280-288.

Söllner, T., Whiteheart, S.W., Brunner, M., ErdjumentBromage, H., Geromanos, S., Tempst, P., and Rothman, J.E. (1993a). SNAP receptors implicated in vesicle targeting and fusion. Nature, 362, 318-324.

Söllner, T., Bennett, M.K., Whiteheart, S.W., Scheller, R.H., and Rothman, J.E. (1993b). A protein assemblydisassembly pathway in vitro that may correspond to sequential steps of synaptic vesicle docking, activation, and fusion. Cell, 75, 409-418.

Sørensen, J.B., Fernández-Chacón, R., Südhof, T.C., and Neher, E. (2003). Examining synaptotagmin1 function in dense core vesicle exocytosis under direct control of $\mathrm{Ca}^{2+}$. J Gen Physiol, 122, 265-276.

Stein, A., Weber, G., Wahl, M.C., and Jahn, R. (2009). Helical extension of the neuronal SNARE complex into the membrane. Nature, 460, 525-528.

Südhof, T.C. (2004). The synaptic vesicle cycle. Annu Rev Neurosci, 27, 509-547.

Südhof, T.C. (2012). The presynaptic active zone. Neuron, $75,11-25$.

Südhof, T.C. (2013a) A molecular machine for neurotransmitter release: Synaptotagmin and beyond. Nature Medicine, 19, 1227-1231. 
Südhof, T.C. (2013b). Neurotransmitter release: The last millisecond in the life of a synaptic vesicle. Neuron, 80 , 675-690.

Südhof, T.C., Lottspeich, F., Greengard, P., Mehl, E., and Jahn, R. (1987). Synaptophysin: A synaptic vesicle protein with four transmembrane regions and a novel cytoplasmic domain. Science, 238, 1142-1144.

Südhof, T.C., Czernik, A.J., Kao, H.T., Takei, K., Johnston, P.A., Horiuchi, A., Kanazir, S.D., Wagner, M.A., Perin, M.S., De Camilli, P., et al. (1989a). Synapsins: mosaics of shared and individual domains in a family of synaptic vesicle phosphoproteins. Science, 245, 1474-1480.

Südhof, T.C., Baumert, M., Perin, M.S., and Jahn, R. (1989b). A synaptic vesicle membrane protein is conserved from mammals to Drosophila. Neuron, 2, 1475-1481.

Südhof, T.C., Fried, V.A., Stone, D.K., Johnston, P.A., and Xie, X.S. (1989c). Human endomembrane $\mathrm{H}^{+}$-pump strongly resembles the ATP-synthetase of archaebacteria. Proc Natl Acad Sci USA, 86, 6067-6071.

Südhof, T.C., and Jahn, R. (1991). Proteins of synaptic vesicles involved in exocytosis and membrane recycling. Neuron, 6, 665-677.

Südhof, T.C., DeCamilli, P., Niemann, H., and Jahn, R. (1993). Membrane fusion machinery: Insights from synaptic proteins. Cell, 75, 1-4.

Südhof T.C., and Rothman, J.E, (2009). Membrane Fusion: Grappling with SNARE and SM Proteins. Science, 323, 474-477.

Sugita, S., Hata, Y., and Südhof, T.C. (1996). Distinct $\mathrm{Ca}^{2+}$ dependent properties of the first and second $\mathrm{C} 2-$ domains of synaptotagmin I. J Biol Chem, 271, 12621265 .

Sugita, S., Han, W., Butz, S., Liu, X., Fernández-Chacón, R., Lao, Y., and Südhof, T.C. (2001). Synaptotagmin VII as a plasma membrane $\mathrm{Ca}^{2+}$-sensor in exocytosis. Neuron, 30, 459-473.

Sugita, S, Shin, O.H., Han, W., Lao, Y., and Südhof, T.C. (2002). Synaptotagmins form a hierarchy of exocytotic $\mathrm{Ca}^{2+}$-sensors with distinct $\mathrm{Ca}^{2+}$-affinities. EMBO J, 21, 270-280.

Sun, J., Pang, Z.P., Qin, D., Fahim, A.T., Adachi, R., and Südhof, T.C. (2007). A Dual $\mathrm{Ca}^{2+}$-Sensor Model for Neuro-transmitter Release in a Central Synapse. Nature, 450, 676-682.

Sutton, R.B., Davletov, B.A., Berghuis, A.M., Südhof T.C., and Sprang, S.R. (1995). Structure of the first C2-domain of synaptotagmin I: A novel $\mathrm{Ca}^{2+}$ /phospholipid binding fold. Cell, 80, 929-938.

Sutton, R.B., Fasshauer, D., Jahn, R., and Brunger, A.T. (1998). Crystal structure of a SNARE complex involved in synaptic exocytosis at $2.4 \AA$ resolution. Nature, 395, 347-353.

Tang, J, Maximov, A, Shin, O.H., Dai, H., Rizo, J., and Südhof, T.C. (2006). A Complexin/Synaptotagmin-1 Switch Controls Fast Synaptic Vesicle Exocytosis. Cell, 126, 1175-1187.
Trimble, W.S., Cowan, D.M., Scheller, R.H. (1988) VAMP-1: a synaptic vesicle-associated integral membrane protein. Proc Natl Acad Sci USA, 85, 4538-4542.

tom Dieck S., Sanmartí-Vila, L., Langnaese, K., Richter, K., Kindler, S., Soyke, A., Wex, H., Smalla, K.H., Kämpf, U., Fränzer, J.T., Stumm, M, Garner, C.C., and Gundelfinger, E.D. (1998). Bassoon, a novel zincfinger CAG/glutamine-repeat protein selectively localized at the active zone of presynaptic nerve terminals. J Cell Biol, 142, 499-509.

Tobaben, S., Thakur, P., Fernández-Chacón, R., Südhof, T.C., Rettig, J., and Stahl, B. (2001). A trimeric protein complex functions as a synaptic chaperone machine. Neuron, 31, 987-999.

Touchot, N., Chardin, P., and Tavitian, A. (1987). Four additional members of the ras gene superfamily isolated by an oligonucleotide strategy: molecular cloning of YPT-related cDNAs from a rat brain library. Proc Natl Acad Sci USA, 84, 8210-8214.

Tsetsenis, T., Younts, T.J., Chiu, C.Q., Kaeser, P.S., Castillo, P.E., and Südhof, T.C. (2011). Rab3B protein is required for long-term depression of hippocampal inhibitory synapses and for normal reversal learning. Proc Natl Acad Sci USA, 108,14300-14305.

Ubach, J., Zhang, X., Shao, X., Südhof, T.C., and Rizo, J. (1998) $\mathrm{Ca}^{2+}$ binding to synaptotagmin: how many $\mathrm{Ca}^{2+}$ ions bind to the tip of a C2-domain? EMBO J., 17, 3921-3930.

Ubach, J., Lao, Y., Fernandez, I., Arac, D., Südhof, T.C., and Rizo, J. (2001) The C2B domain of synaptotagmin $\mathrm{I}$ is a $\mathrm{Ca}^{2+}$-binding module. Biochemistry, 40, 5854-5860.

Varoqueaux, F., Sigler, A., Rhee, J.S., Brose, N., Enk, C., Reim, K., and Rosenmund, C. (2002). Total arrest of spontaneous and evoked synaptic transmission but normal synaptogenesis in the absence of Munc13mediated vesicle priming. Proc Natl Acad Sci USA, 99, 9037-9042.

Verhage, M., Maia, A.S., Plomp, J.J., Brussaard, A.B., Heeroma, J.H., Vermeer, H., Toonen, R.F., Hammer, R.E., van den Berg, T.K., Missler, M., Geuze, H.J., and Südhof, T.C. (2000). Synaptic assembly of the brain in the absence of neurotransmitter secretion. Science, $287,864-869$.

Voets, T., Moser, T., Lund, P.E., Chow, R.H., Geppert, M., Südhof, T.C., and Neher, E. (2001). Intracellular calcium dependence of large dense-core vesicle exocytosis in the absence of synaptotagmin I. Proc Natl Acad Sci USA, 98, 11680-11685.

von Mollard, G.F., Mignery, G.A., Baumert, M., Perin, M.S., Hanson, T.J., Burger, P.M., Jahn, R., and Südhof, T.C. (1990). Rab3 is a small GTP-binding protein exclusively localized to synaptic vesicles. Proc Natl Acad Sci USA, 87, 1988-1992.

von Mollard, G.F., Südhof, T.C., and Jahn, R. (1991). A small GTP-binding protein (rab3A) dissociates from synaptic vesicles during exocytosis. Nature, 349, 79-81. 
Wang, X., Kibschull, M., Laue, M.M., Lichte, B., PetraschParwez, E., and Kilimann, M.W. (1999). Aczonin, a $550-\mathrm{kD}$ putative scaffolding protein of presynaptic active zones, shares homology regions with Rim and Bassoon and binds profilin. J Cell Biol, 147, 151-162.

Wang, Y., Okamoto, M., Schmitz, F., Hofmann, K., and Südhof, T.C. (1997). RIM: A putative Rab3-effector in regulating synaptic vesicle fusion. Nature, 388, 593-598.

Wang, Y., Sugita, S., and Südhof, T.C. (2000). The RIM/NIM family of neuronal SH3-domain proteins: interactions with Rab3 and a new class of neuronal SH3-domain proteins. J Biol Chem, 275, 20033-20044.

Wang, Y., Liu, X., Biederer, T., and Südhof, T.C. (2002). A family of RIM-binding proteins regulated by alternative splicing: Implications for the genesis of synaptic active zones. Proc Natl Acad Sci USA, 99, 14464-14469.

Weber, T., Zemelman, B.V., McNew, J.A., Westermann, B., Gmachl, M, Parlati, F., Söllner, T.H., and Rothman, J.E. (1998). SNAREpins: minimal machinery for membrane fusion. Cell, 92, 759-772.

Wen, H., Linhoff, M.W., McGinley, M.J., Li, G.L., Corson, G.M., Mandel, G., and Brehm, P. (2010). Distinct roles for two synaptotagmin isoforms in synchronous and asynchronous transmitter release at zebrafish neuromuscular junction. Proc Natl Acad Sci USA, 107, 13906-13911.

Whittaker, V.P., and Sheridan, M.N. (1965). The morphology and acetylcholine content of isolated cerebral cortical synaptic vesicles. J Neurochem, 12, 363-372.

Wilson, D.W., Wilcox, C.A., Flynn, G.C., Chen, E., Kuang, W.J., Henzel, W.J., Block, M.R., Ullrich, A., and Rothman, J.E. (1989). A fusion protein required for vesicle-mediated transport in both mammalian cells and yeast. Nature, 339, 355-359.

$\mathrm{Xu}$, J., Mashimo, T., and Südhof, T.C. (2007). Synaptotagmin-1, -2 , and -9 : $\mathrm{Ca}^{2+}$-sensors for fast release that specify distinct presynaptic properties in subsets of neurons. Neuron, 54, 801-812.
Xu, J., Pang, Z.P., Shin, O.H., and Südhof, T.C. (2009). Synaptotagmin-1 functions as a $\mathrm{Ca}^{2+}$ sensor for spontaneous release. Nature Neurosci, 12, 759-766.

Xu, W., Morishita, W., Buckmaster, P.S., Pang, Z.P., Malenka, R.C., and Südhof, T.C. (2012). Distinct Neuronal Coding Schemes in Memory Revealed by Selective Erasure of Fast Synchronous Synaptic Transmission. Neuron, 73, 990-1001.

Xue, M., Reim, K., Chen, X., Chao, H.T., Deng, H., Rizo, J., Brose, N., and Rosenmund, C. (2007). Distinct domains of complexin I differentially regulate neurotransmitter release. Nat Struct Mol Biol, 14, 949-958.

Yamaguchi, T., Dulubova, I., Min, S.W., Chen, X., Rizo, J., and Südhof, T.C. (2002). Sly1 binds to Golgi and ER syntaxins via a conserved N-terminal peptide motif. Developmental Cell, 2, 295-305.

Yang, X., Kaeser-Woo, Y.J., Pang, Z.P., Xu, W., and Südhof, T.C. (2010). Complexin Clamps Asynchronous Release by Blocking a Secondary $\mathrm{Ca}^{2+}$-Sensor via its Accessory a-Helix. Neuron, 68, 907-920.

Yang, X., Cao, P., and Südhof, T.C. (2013). Deconstructing complexin function in activating and clamping $\mathrm{Ca}^{2+}$-triggered exocytosis by comparing knockout and knockdown phenotypes. Proc Natl Acad Sci USA, 110, 20777-20782.

Zhen, M., and Jin, Y. (1999). The liprin protein SYD-2 regulates the differentiation of presynaptic termini in C. elegans. Nature, 401, 371-375.

Zhou, P., Pang, Z.P., Yang, X., Zhang, Y., Rosenmund, C., Bacaj, T., and Südhof, T.C. (2013a). Syntaxin-1 NPeptide and Habc-Domain Perform Distinct Essential Functions in Synaptic Vesicle Fusion. EMBO J, 32, 159-171.

Zhou, P., Bacaj, T., Yang, X., Pang, Z.P., and Südhof, T.C. (2013b). Lipid-Anchored SNARE Lacking Transmembrane Regions Support Membrane Fusion During Neurotransmitter Release. Neuron, 80, 470-483.

Zimmermann, H., and Whittaker, V.P. (1997). Morphological and biochemical heterogeneity of cholinergic synaptic vesicles. Nature, 267, 633-635. 